\title{
Spatio-temporal effects of an urban development announcement and its cancellation on house prices - A quasi-natural experiment
}

\author{
Dongwoo Hyun \\ Real Estate and Planning, University of Reading, UK \\ Whiteknights, Reading, RG6 6UD, United Kingdom \\ e-mail: d.hyun@pgr.reading.ac.uk
}

\author{
Stanimira Milcheva \\ Bartlett School, University College London \\ 1-19 Torrington Place, WC1E 7HB \\ e-mail: s.milcheva@ucl.ac.uk
}

\begin{abstract}
We use a spatio-temporal autoregressive difference-in-differences (SDID) framework to assess the strength of announcement effects associated with an urban development on house prices over time and across locations. The quasi-natural experimental setting of a large-scale urban redevelopment project in Seoul, South Korea, announced in 2007 and cancelled six years later without any construction having taken place, allows us to cleanly disentangle the announcement affect from the actual development effect. Using more than 21,000 apartment transactions between 2006 and 2015, we find that the development announcement increases apartment prices between $2.4 \%$ and $7.3 \%$ for properties within $1 \mathrm{~km}$ radius of the project site. However, for buildings beyond $1 \mathrm{~km}$, the effect becomes negative suggesting spatial redistribution of housing demand. The cancellation of the project leads to a significantly decline in prices between $3.5 \%$ and $5.2 \%$ for apartments within $1 \mathrm{~km}$ from the project site nearly cancelling the associated positive effects. We find that properties which are located around the project site but are not in direct proximity actually have a significant price cut after each announcement. Overall, we show that announcement and cancellation of development projects have a significant impact on residential property prices near the site but vary considerably in strength and direction across space.

JEL classification: C21, R15, R31, R53
\end{abstract}

Keywords: Announcement effect, spatial spillover, spatio-temporal autoregressive model, difference-indifferences, apartment transaction prices. 


\section{Introduction}

Tiebout (1956) argues that facing an array of communities that offer different types and levels of public services and amenities, each individual household will move from one local community to another to maximise their utility. This process known as "voting with their feet" can explain the heterogeneity of house price levels among communities. Higher level of house prices in a certain community reflects better provision of public services and amenities in the community via higher willingness to pay for purchasing or renting a house by households. Starting with Oates (1969), a large number of empirical research tests the Tiebout theory and finds that the development of a new amenity has a significant impact on surrounding house prices. For example, amenities such as a new transit line or a sports stadium may have an overall positive impact on surrounding residential prices ${ }^{1}$, whereas other facilitates, such as landfill, power plants or airports, may have a negative effect on the value of the surrounding residential properties ${ }^{2}$. Some studies ${ }^{3}$ show that the overall effect from a development or an amenity (the development effect or the amenity effect) begins to be capitalised into property prices surrounding the development site as early as the first announcement of the development. This is due to the anticipation of future housing value growth after the completion of the development (McMillen and McDonald, 2004). Since property prices show this early response to news about developments, developers, government bodies and politicians need to be careful with this transmission mechanism to house prices as prices can be affected even without any construction taking place at all. What is the size of such purely announcement effects will be the focus of this paper.

While a number of studies has quantified effects associated with the announcement of new developments or amenities, such developments in deed take place and hence the anticipated house price increases are just capitalised somewhat earlier. We are interested in quantifying the effect on prices simply following an announcement of a new development and disentangling it from the actual development effect. This we call the announcement effect. However, assessing whether and to what degree the announcement effect exists is empirically challenging for various reasons. First, it is difficult to isolate the announcement effect from the effect of the actual development as those go hand in hand. As the development takes a long time, house prices can be influenced by incidental developments such as building a new road prior to the full completion of the amenity. House price changes can occur from the moment of announcement of the project throughout the whole construction phase and eventually event afterwards if the value of the project is over- or underestimated (McMillen and McDonald, 2004). Such price adjustments occur only gradually throughout the development process. Thus, it is not straight

\footnotetext{
${ }^{1}$ See Gatzlaff and Smith (1993), McDonald and Osuji (1995), Bowes and Ihlanfeldt (2001), McMillen and McDonald (2004), Gibbons and Machin (2005), Tu (2005), Dehring et al. (2007), Ahlfeldt and Maennig (2009), Kavetsos (2012) and Dubé et al. (2014).

${ }^{2}$ See Michaels and Smith (1990), Kohlhase (1991), Kiel (1995), Tomkins et al. (1998), Nelson (2004), Jud and Winkler (2006), Cohen and Coughlin (2008), Dröes and Koster (2016) and Bauer et al. (2017).

${ }^{3}$ We discuss the studies in Section 2.
} 
forward to define the cut-off point of when the announcement effect ends and the development effect takes over (that is, the announcement effect period, see Ahlfeldt and Kavetsos (2014), Immergluck (2009)). This is even harder to identify for large-scale urban development projects, which may include multiple facilities and take dozens of years. Second, the announcement effect may vary in strength depending on the location of the properties in relation to the project site. We can observe spatial spillovers across property markets and spatial dependence in property prices following the announcement effect suggesting that some house price changes may not be associated with the announcement effects but rather with the spatial effects of house price changes. ${ }^{4}$

In this paper, we quantify the announcement effect of an urban redevelopment project by using a quasi-natural experiment. We investigate the Yongsan International Business District (YIBD) project in Seoul, South Korea. What makes this project unique is that after it was officially announced in 2007 no further action and no construction has been taken and the development has been cancelled six years later. In August 2007, the Seoul metropolitan government announced for the first time the YIBD redevelopment. The main aim of the project was to turn a deprived downtown area of $515,483 \mathrm{~m}^{2}$ $\left(356,000 \mathrm{~m}^{2}\right.$ of which was a railroad maintenance depot and the rest, a residential area) into a global business district similar to the one in Roppongi Hills, Tokyo, and Canary Wharf, London. Totalling approximately $\$ 28.2$ billion $^{5}$, the project was planned to develop commercial, retail, leisure and hotels. The announcement of the YIBD is enough to give rise to a constellation of the anticipation about future housing value growth near the project site. The project is to turn a huge land plot of dis-amenity facilities in the central urban area into amenity facilities. Most of the project site is a railway maintenance depot which is undesirable in an urban residential area due to noise and air pollution. The project would be expected to improve residential environment substantially by not only demolishing the dis-amenity facilities but also providing a number of aesthetic skyscrapers and consumption benefits from various facilities. Furthermore, after the official development announcement, the project labelled 'the priciest real estate development project in the history of Korea ${ }^{6}$, was frequently exposed to the public by mass media. In April 2013, the cancellation of the project was announced. Two factors are generally pointed out as primary causes of the project failure - the economic recession after the 2008 global financial crisis and the intense conflicts among the investors. During the 67-month period between the development announcement and the cancellation announcement, the project site consolidation had been conducted, however the construction of visible structures was not commenced.

\footnotetext{
${ }^{4}$ For example, housing sellers who observe an increase in housing transaction prices in a neighbourhood due to the announcement effect may ask the premium even if they have no idea why the neighbouring property prices increase or do not realise the development or announcement but just because the properties are in the same neighbourhood.

${ }^{5}$ The currency in this paper corresponds the US Dollar based on the exchange rate of 1,100 Korean Won for 1 USD.

6 "Seoul Stays Stuck in a Bad 'Dream"”, The Wall Street Journal, 29 April, 2014.
} 
We quantify the effect on house prices associated with two types of announcements - positive announcements of a new urban development and negative announcements of the cancellation of the development. We examine whether the announcement is capitalised into house prices by comparing transaction prices of properties surrounding the project site before and after the announcement. If the residential price changes are mainly driven by the anticipation of the development, then those should be offset with the cancellation of the project. A cancellation of the project is expected to result in an immediate and sharp price decline without any adjustment period. This can be compared to the effects from a collapse of a speculative housing bubble. Therefore, the bigger the announcement effect, the larger the negative impact of the cancellation would be on house prices. Assuming that the Seoul housing market is relatively efficient ${ }^{7}$ given the short-term inelastic supply of new housing, the capitalisation in house prices following the announcement effects would be substantially prominent and rapid (Gibbons and Machin, 2005; Glaeser et al., 2008; Mian and Sufi, 2009). Thus, we would not expect a significant net change in house prices after the two announcements. ${ }^{8}$

We assume that the changes in property prices near the project site following the announcement would embed all positive and negative externalities expected by the development. Therefore, the announcement effects can be principally inferred from the spatial variation in the transaction prices of residential properties surrounding the development site after the announcements. For this purpose, we use a spatial difference-in-differences (DID) approach. A DID methodology essentially compares two samples of data - a treatment group and a control group - compared in two subperiods -before and after the announcement. The treatment group in our case consists of the apartment transactions in the 'impact' area, the area closest to the redevelopment site. The control sample comprises of the properties in the 'control' area, which is located further away from the project site where property prices are unlikely to be affected by the development. This quasi-experimental approach controls for the possible omission of significant variables correlated with the announcement effect (Ahlfeldt and Kavetsos, 2014; Gibbons and Machin, 2005; Pope and Pope, 2015). We apply the DID setting into a spatio-temporal autoregressive model (STAR), which we call the spatial DID model (SDID), rather than estimating a classic DID hedonic price model (HDID). The SDID looks at spatial dependence between transaction

\footnotetext{
${ }^{7}$ First, the market is transparent in terms of easy access to information on individual housing transactions. There is a large number of real estate brokers in neighbourhoods (normally multiple brokers within a single apartment complex), and they provide daily updated information of housing transactions in the neighbourhood. Second, the homogeneity of properties allows sellers and buyers to compare the quality of properties as well as those transaction prices. Apartments are typically constructed within a large complex of multi-storey buildings with highly standardised floor plans, building materials and structures, and complex amenities. Third, the market is liquid. Transaction costs are relatively low (mainly composed of brokerage fees of up to $0.9 \%$ of the transaction price) and the homogeneity of property keeps searching costs low, hence transactions are quite frequent (Hwang et al., 2006; Hyun and Milcheva, 2018).

${ }^{8}$ The cancellation of the development may not necessarily lead to a zero net announcement effect. Individuals still may anticipate some form of construction at a later stage. However, given the large uncertainly with any future development in the respective area, we can assume that those expectations should not have strong fundamental grounds and hence would negligible.
} 
prices in the impact area and the control area. Thus, the SDID controls for the spatial autocorrelation effects across house prices which may not be directly related to the announcement.

We use apartment transaction data from the Ministry of Land of South Korea, covering all 21,200 apartment transactions in the area of interest between 2006 and 2015. The results provide strong evidence for the existence of significant announcement effects. Following the announcement of the redevelopment, apartment prices within $0.5 \mathrm{~km}$ from the project site increase by $7.3 \%$ relative to comparable apartments located $3-3.5 \mathrm{~km}$ away from the project site. However, for buildings further away from the site, the positive announcement effect has a negative effect on house prices suggesting spatial redistribution of housing demand. A cancellation of the project leads to a significantly decline in prices between $1.5 \%$ and $5.2 \%$ for apartments within $1.5 \mathrm{~km}$ from the project site. Those results suggest that both, positive and negative announcement effects of development projects have large impact on house prices and vary considerably in strength and direction across space.

The rest of this study is structured as follows. Section 2 provides an overview of the related literature. Section 3 offers background information on the YIBD project. Section 4 and 5 describe the data and methodology respectively. Section 6 presents the empirical results and Section 7 concludes.

\section{Literature review}

The empirical research suggests that externalities caused by a new amenity development are capitalised into housing values in adjacent areas, and the capitalisation begins, at least partially, before the construction is physically initiated or completed. This is implicitly based on an assumption that housing markets are informationally efficient, hence expected externalities are capitalised in house prices sufficiently in advance of the implementation of the development. In order to estimate the effects, empirical studies compare house prices in different periods.

Gatzlaff and Smith (1993) examine the impact of the metro-rail system development on residential property values in Miami. Using the year of 1980 as an intervention date when the development plan is announced, the empirical results suggest relatively weak announcement effect, with coefficients which are not significantly different. McDonald and Osuji (1995) examine the anticipation effect of transit improvement on residential land values in Chicago. They take the year of 1980 as the 'before' period when the public realise that the new transit line might be built but sites for station are veiled and the year of 1990, three years prior to the opening of the new transit line, as the 'after' period when the station sites are unveiled to the public and the stations are under construction and visible. For the after period relative to the before period, they find 17\% higher value of residential land values within 0.5 miles from the new stations.

Colwell et al. (2000) examine the dis-amenity impact of group homes on neighbouring property values in Illinois. They compare house prices six years before and after the announcement of the plan. 
The announcement date is the time at which neighbours become aware that a group home will be built in their neighbourhood. The results show a decline in the value of the properties in which the group home is visible (approximately 10.5\%) and the properties located within 200 feet from the facility (approximately 24\%) following the announcement of a group home's pending establishment. Dehring et al. (2007) investigate the impact of a new publicly subsidised sports stadium construction on the value of residential properties in Dallas. They find that residential property values increase in the host area at city level, whereas decrease at the local level following the announcement of a potential new stadium construction. They conclude that the negative impact at local level is associated with the expected additional local sale tax burden.

Immergluck (2009) examines the anticipation effects of a large urban redevelopment initiative on housing values in Atlanta. The 6500-acre project including development of light rail line, greenspace and real estate projects provides price premiums of approximately $15 \%-30 \%$ for locations within a quarter-mile from the project site, with impacts falling off beyond a quarter-mile. The premium effect spreads over four years of the pre-development period. Kavetsos (2012) assesses the impact of the 2012 Olympic bid on property prices in London. The study compares property prices before and after the announcement of the winning bid. London's successful Olympics bid has a substantial impact on property values; properties in host boroughs sell at up to $3.3 \%$ higher than non-host boroughs; house prices within 3 miles from the main stadium increases by $5 \%$ on average.

Ahlfeldt and Kavetsos (2014) find significant house price changes following the announcement of the sports stadia construction plan. They first estimate house price trends and find clearer price changes after the announcement of the general plan than after the completion of construction. Based on this finding, they set the announcement date as the intervention date. The results show a $16.4 \%$ increase in property prices following the announcement of the new Wembley stadium development in London, whereas a 7.6\% decrease following the announcement of the Emirates stadium development in London. Bauer et al. (2017) examine the negative impact of nuclear power plants (NPPs) on local housing values in Germany. The study uses the date of the Fukushima NPP accident in Japan as a cut-off point for the DID analysis. They find that housing values in the vicinity of NPPs that were already in operation when the Fukushima accident happened fall by approximately $5 \%$ following the accident in Japan. Housing prices near NPP sites that were shut down after the Fukushima accident decrease by $9.8 \%$.

Overall, the empirical literature presents evidence on the announcement effect by showing noticeable price changes before and after the announcement of the development. However, above research looks at cases that make construction progress steadily after the announcement and/or complete the construction. This study differs in that no physical development has taken place after the announcement. Therefore, we can rule out development-associated price effects from the announcement effect. Moreover, the existing literature controls the presence of spatial autocorrelation in the residuals 
by employing a DID analysis, however it does not directly control for spatial dependence in dependent variable (i.e. house prices). This study also adds to the literature by controlling for spatial autocorrelation in house prices using a spatial DID approach.

\section{The Yongsan International Business District Project}

The Yongsan International Business District project was meant to be South Korea's priciest real estate development project, totalling approximately $\$ 28.2$ billion. It was to be located in the borough of Yongsan, which belongs to one of Seoul's centrally located boroughs. The project aimed to develop $515,483 \mathrm{~m}^{2}$ of land into a vibrant mixed-use hub with twelve commercial high-rise buildings, including a landmark 111-story building, seven residential complexes, hotels, shopping malls and department stores. The construction would have commenced in December 2011 and been completed by September 2016. The expected total value added through the development was estimated at approximately $\$ 60.9$ billion with 360,000 jobs created and a population of 140 million including tourists. The gigantic project, however, halted and all contracts and agreements upon the project were cancelled in April 2013, six years after the general plan was unveiled to the public.

A proportion of the land (approximately $356,000 \mathrm{~m}^{2}$ ) was originally assigned for the development of a railroad maintenance depot by the Korean National Railroad (Korail), the state-run rail operator. The main aim of the original project was to settle the company's debt of $\$ 4.09$ billion through the disposal of a highly valued land ( $\$ 3.45$ billion) in the centre of Seoul. Korail submitted the general development plan to the Seoul Metropolitan Government (SMG) for approval. According to the SMG, the then Mayor of Seoul suggested an extensive integrated development around the project site which included $159,000 \mathrm{~m}^{2}$ of the neighbouring residential area Seobu-Ichondong as a condition for the approval. Since then, SMG took a leading role to establish a consortium, and the nature of the development was expanded to a large-scale urban redevelopment.

On 17 August 2007, SMG and Korail announced the general plan of the Yongsan International Business District project. In December 2007, a project finance company called Dream Hub was established with $\$ 909$ million from two public investors (29.9\%), six strategic investors (25.5\%), five financial investors (24.6\%) and seventeen construction investors (20\%). The asset management company, the Yongsan Development Corporation, was also established by the consortium. The main issue was the financing of the land purchase as the payment increased from $\$ 3.45$ billion to $\$ 7.27$ billion due to the expansion of the project site from $356,000 \mathrm{~m}^{2}$ to $515,483 \mathrm{~m}^{2}$ (an increase of $159,000 \mathrm{~m}^{2}$ of the Seoubu-Ichondong residential area). The debt investors requested guarantees of the construction companies as it is customary in South Korea that project finance is based upon the balance sheets and guarantees of the construction company rather than the projected cash flows of the project. However, Samsung Construction and Trading Corporation (Samsung C\&T), the largest shareholder in the asset management company, as well as one of construction companies, strongly opposed the guarantee 
request and withdrew from the company in September 2010. All shares of Samsung C\&T (45.1\%) in were transferred to Lotte Development Corporation, the second largest shareholder, becoming the largest shareholder with a stake of $70.1 \%$. Following above events, Dream Hub and Korail announced in July 2011 the new plan for the project realisation.

The project seemed to be progressing smoothly with the announcement of a master plan and schematic design in May 2012 as well as the announcement of a compensation plan for the displaced residents in August 2012. However, the conflicts among the shareholders (Korail and Lotte Decelopment Corporation) about an increase in the equity, the financing of residents' compensation, issuing convertible bonds, changes in the development approach and the management of the company. On 12 March 2013, Dream Hub default on an interest payment of its repayment of the asset backed commercial paper of $\$ 4.73$ million. Three days later, Korail proposed an alternative plan for the project realisation. However, the proposal was rejected by the board of directors in the consortium on 5 April 2013. On 29 April 2013, Korail cancelled the land contract and the development agreement.

\section{Data}

This study uses apartment transaction data from the Ministry of Land of South Korea. Apartments account for the vast majority of residential property in Seoul, comprising $58.60 \%$ of the total number of residential properties as of 2015. Each transaction record contains the apartment unit transaction price, address, floor, size, year of construction and date of the transaction. Our data cover all transactions from January 2006 to December 2015. While the total number of transactions in that period is 21,416, 216 transactions are missing key information, hence we end up with 21,200 transactions. Additional property variables, which are not available from the Ministry of Land, are obtained from three Korean property websites covering the residential market: Naver Real Estate, R114 and DrApt. The final data includes the standard variables that explain house price variation in most housing studies (e.g., size, age of property, number of rooms, bathrooms and parking space, floor level, heating system and proximity to public transport) as well as unique characteristics of the Seoul apartment market (e.g. number of buildings and apartment units, whether an apartment is constructed by one of ten largest construction companies (reputation) ${ }^{9}$, whether an apartment builder is a public

\footnotetext{
${ }^{9}$ We label this dummy variable 'reputation', meaning that the top developers may be associated with higher reputation among the market agents. The selection of top 10 builders is based on an average turnover ranking during the ten years of the sample. The composition of the top ten ranking remains the same throughout the entire period, with some changes in position of each firm with the ranking.
} 
owned company, whether a property is in a complex, whether registered low rental units are within a building/complex and whether an apartment building/complex has permission for reconstruction ${ }^{10}$ ).

The key variable to assess the announcement effect is the proximity of a property to the project site. We infer the announcement effect from the spatial variation of apartment transaction prices surrounding the project site. There is no consensus in the empirical research on the role of the distance threshold for the amenity development effect on house prices. In general, significant results are obtained with a distance threshold between $2 \mathrm{~km}$ and $5 \mathrm{~km}$ (1.5miles and 3 miles $)^{11}$. We set the threshold at $3.5 \mathrm{~km}$ from the project site which is based on preliminary hedonic models with distance dummy variables indicating the proximity of a property to the project site. We find no statistically significant effects beyond the $3.5 \mathrm{~km}$ threshold. We use two measurements for distance - 1) a linear distance and 2) nonlinear radius ring distances which are consecutive and mutually exclusive. Both measures are based on the Euclidean distance between a property and the centre point of the project site. Given the high density in the urban area of interest, we choose a $0.5 \mathrm{~km}$ ring intervals after looking at the spatial distribution of the transactions and ensuring an even number of observations within each distance ring ${ }^{12}$. We define a total of seven rings within a radius of $3.5 \mathrm{~km}$ (Fig. 1). The first six rings located within $3 \mathrm{~km}$ from the project site form part of the impact area whereas the farthest ring $(3 \mathrm{~km}-3.5 \mathrm{~km})$ acts as a natural control group. The distance from a property to the project site is measured by the geographic information system (GIS) using geographic coordinates of each property. For the ring specification, dummy variables are used to indicate whether the property is located in the respective ring area. Following a standard DID estimation procedure, several interaction variables are used to estimate the announcement effect. A list of the variables used in the estimation and their definitions is provided in Table 1.

\footnotetext{
${ }^{10}$ Reconstruction of apartment (complex) defines that: in accordance with the procedures described in existing laws, existing owners of multi-family housing voluntarily form an association for redevelopment, demolish deteriorated existing housing and construct new housing jointly with construction firms on the site where existing multi-family homes were built (Lee et al., 2005, p.59). This variable reflects expectations about future housing value growth after reconstruction.

${ }^{11}$ For example, a 2km threshold (Ahlfeldt, 2011; Gibbons and Machin, 2005) and a 1.5mile threshold (McDonald and Osuji, 1995; McMillen and McDonald, 2004) is used for the railway development respectively. Significant impacts of sports stadium development are found with a 2.5mile threshold (Coates and Humphreys, 2006), a 3mile threshold (Kavetsos, 2012; Tu, 2005) and a 5km threshold (Ahlfeldt and Kavetsos, 2014). Hoen et al. (2015) and Dröes and Koster (2016) use a 3 mile and $2 \mathrm{~km}$ threshold for the wind energy facility respectively.

${ }^{12}$ The data includes 295 observations within $0.5 \mathrm{~km}$ from the project site, 1781 observations between $0.5 \mathrm{~km}$ and $1 \mathrm{~km}, 5389$ observations between $1 \mathrm{~km}$ and $1.5 \mathrm{~km}, 3601$ observations between $1.5 \mathrm{~km}$ and $2 \mathrm{~km}, 5370$ observations between $2 \mathrm{~km}$ and $2.5 \mathrm{~km}, 2551$ observations between $2.5 \mathrm{~km}$ and $3 \mathrm{~km}$ and 2213 observations between $3 \mathrm{~km}$ and $3.5 \mathrm{~km}$. We find a better model fit using the six rings than using five rings with the first two rings combined together.
} 
Fig. 1. Spatial dispersion of apartment transactions (at building level) between 2006 and 2015 around the planned development Yongsan International Business District, Seoul, South Korea

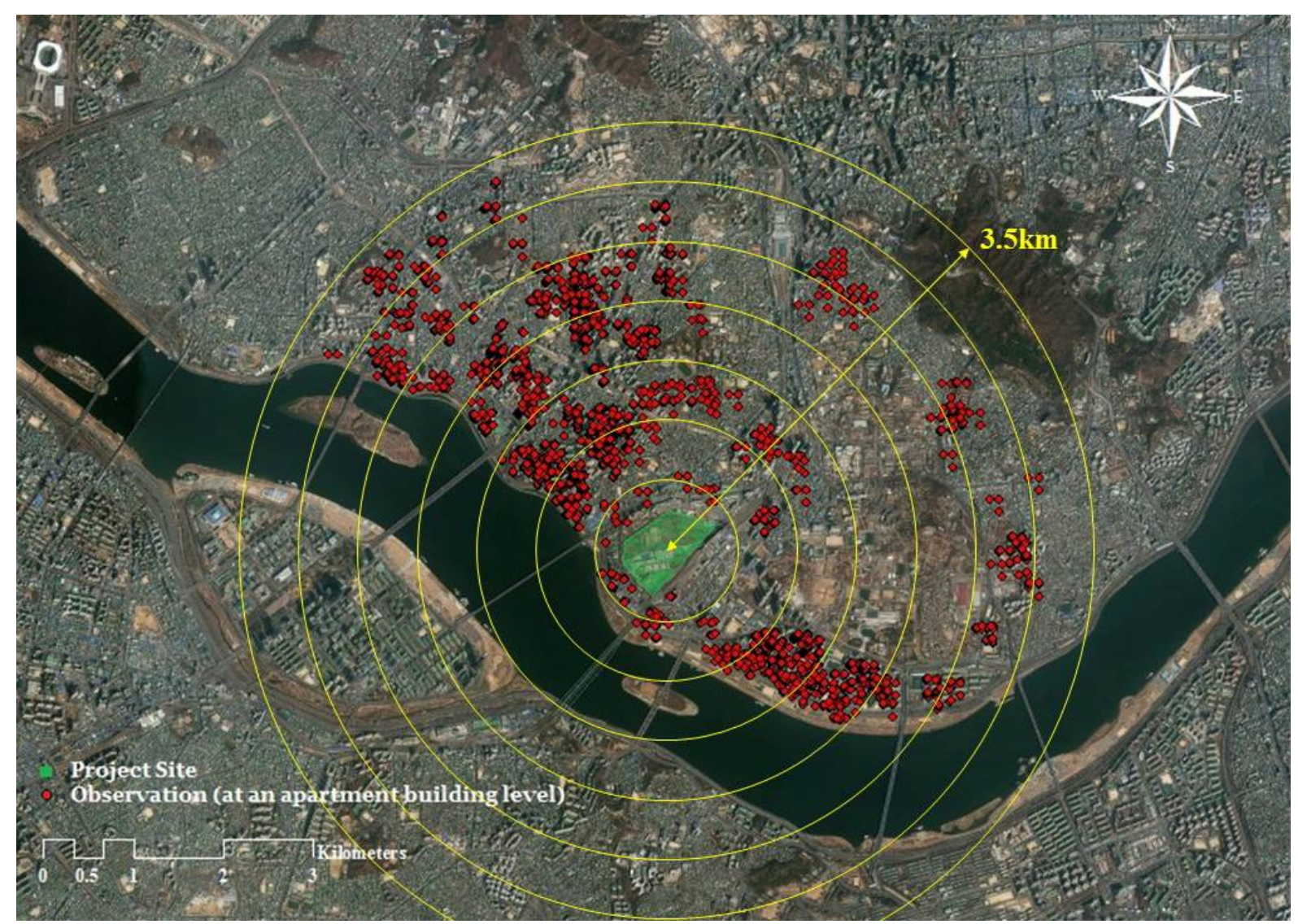

Source: Adapted from ESRI (www.arcgis.com). Note: Each ring has a radius of $0.5 \mathrm{~km}$ from the centre of the project site (highlighted in the middle)

\section{Methodology}

The methodology consists of three steps. In the first step, a baseline hedonic price model is developed to explain apartment prices as a function of a set of property-specific characteristics and locational attributes. Then the hedonic model is extended to capture spatial autocorrelation in transaction prices. We use the spatial hedonic model to analyse apartment prices for the period before the development announcement (pre-DA), for the period following the development announcement (post-DA) and the period after the cancellation announcement (post-CA) respectively. In the second step, the spatial hedonic model is augmented by an interaction term which is the product of a time dummy variable and a distance variable in order to capture time-varying announcement effects. In the third step, we include a DID estimator in the spatial hedonic model to assess the announcement effect. The DID analysis is conducted for the period 1) before and after the development announcement and 2) before and after the cancellation announcement.

\section{Baseline hedonic price model (HPM) and spatio-temporal autoregressive model (STAR)}


Table 1

Variable description

\begin{tabular}{|c|c|}
\hline Variable & Description \\
\hline \multicolumn{2}{|l|}{ Dependent Variable } \\
\hline (Log) Price & (Logarithm of) Transaction price of a single apartment unit within an apartment building \\
\hline \multicolumn{2}{|c|}{ Independent Variable } \\
\hline Size & Net floor area of an apartment unit in square metres \\
\hline Floor & The floor level on which an apartment unit is located within the apartment building \\
\hline Rooms & Number of rooms \\
\hline Bathrooms & Number of bathrooms \\
\hline Age & Difference in years between the year of transaction of the given apartment unit and the year of construction of the apartment building \\
\hline Age squared & Square of the age \\
\hline Buildings & $\begin{array}{l}\text { Number of apartment buildings in an apartment complex in which the apartment unit is situated. In case the apartment unit is not part of } \\
\text { a complex, the value is one }\end{array}$ \\
\hline Units & Number of apartment units in the apartment building/complex \\
\hline Parking & Number of parking spaces per apartment unit \\
\hline Heating $^{+}$ & Equal to one if an apartment building has central heating and zero otherwise \\
\hline Complex ${ }^{+}$ & Equal to one if an apartment unit is located in an apartment complex consisting of several apartment buildings and zero otherwise \\
\hline Subway & Distance in metres (measured as a straight line) from an apartment building to the nearest subway station \\
\hline Reputation+ & $\begin{array}{l}\text { Equal to one if an apartment building/complex is constructed by one of the ten largest construction companies (all of them are domestic } \\
\text { developers) and zero otherwise }\end{array}$ \\
\hline Public Company $^{+}$ & Equal to one if an apartment building/complex is constructed by a publicly owned construction company and zero otherwise \\
\hline Low-rental $^{+}$ & Equal to one if there are any apartment units registered as social housing within the apartment building/complex and zero otherwise \\
\hline Permission $^{+}$ & $\begin{array}{l}\text { Equal to one if an apartment building/complex has obtained a permission for reconstruction but before the reconstruction has begun and } \\
\text { zero otherwise }\end{array}$ \\
\hline Year $^{+}$ & Yearly time dummy variable, equal to one if an apartment unit is sold in the respective year and zero otherwise \\
\hline
\end{tabular}




\begin{tabular}{|c|c|}
\hline Variable & Description \\
\hline Location $^{+}$ & $\begin{array}{l}\text { Location dummy variable on the smallest administrative district in South Korea }{ }^{13} \text { ( } 39 \text { districts in Seoul), equal to one if an apartment } \\
\text { is located in the respective district and zero otherwise }\end{array}$ \\
\hline Distance & $\begin{array}{l}\text { Distance in kilometres (measured as the Euclidean distance using longitude and latitude) from an apartment unit to the centre point of } \\
\text { the project site }\end{array}$ \\
\hline Ring0.5+ & Equal to one if an apartment unit is located within a $0.5 \mathrm{~km}$ radius from the project site and zero otherwise \\
\hline Ring $1^{+}$ & Equal to one if an apartment unit is located between $0.5 \mathrm{~km}$ and $1 \mathrm{~km}$ radius from the project site and zero otherwise \\
\hline Ring1.5 & Equal to one if an apartment unit is located between $1 \mathrm{~km}$ and $1.5 \mathrm{~km}$ radius from the project site and zero otherwise \\
\hline Ring $2^{+}$ & Equal to one if an apartment unit is located between $1.5 \mathrm{~km}$ and $2 \mathrm{~km}$ radius from the project site and zero otherwise \\
\hline Ring $2.5^{+}$ & Equal to one if an apartment unit is located between $2 \mathrm{~km}$ and $2.5 \mathrm{~km}$ radius from the project site and zero otherwise \\
\hline Ring $3^{+}$ & Equal to one if an apartment unit is located between $2.5 \mathrm{~km}$ and $3 \mathrm{~km}$ radius from the project site and zero otherwise \\
\hline Ring $3.5^{+}$ & Equal to one if an apartment unit is located between $3 \mathrm{~km}$ and $3.5 \mathrm{~km}$ radius from the project site and zero otherwise \\
\hline Post-DA ${ }^{+}$ & Equal to one if an apartment unit is transacted between August 2007 and March 2013 and zero otherwise \\
\hline Post-CA ${ }^{+}$ & Equal to one if an apartment unit is transacted between April 2013 and December 2015 and zero otherwise \\
\hline D_Year & Interaction term, Distance times Year \\
\hline R_Year ${ }^{+}$ & Interaction term, $\operatorname{Ring}(0.5$ to 3.5 respectively) times Year \\
\hline D_Post-DA & Interaction term, Distance times Post-DA \\
\hline R_Post-DA ${ }^{+}$ & Interaction term, $\operatorname{Ring}(0.5$ to 3.5 respectively) times Post-DA \\
\hline D_Post-CA & Interaction term, Distance times Post-CA \\
\hline R_Post-CA ${ }^{+}$ & Interaction term, $\operatorname{Ring}(0.5$ to 3.5 respectively) times Post-CA \\
\hline
\end{tabular}

Note: ${ }^{+}$dummy variable.

\footnotetext{
13 'Dong' in Korean.
} 
The first specification is given by a standard hedonic analysis as specified by Rosen (1974, p.34) that "goods are valued for their utility-bearing attributes or characteristics." In this framework, an apartment price is determined by a function of the level of physical and locational property characteristics and the proximity to the project site. Two hedonic equations are specified according to the two types of distances, the linear distance and the radius ring distances, as follows:

$$
\begin{aligned}
& \log \left(P_{i t}\right)=c+\alpha D_{i t}+\sum_{k} \beta_{k} H_{i t k}+\sum_{y} \delta_{y} Y_{i t y}+\sum_{l} \varphi_{l} L_{i t l}+\varepsilon_{i t} \\
& \log \left(P_{i t}\right)=c+\sum_{r} \gamma_{r} R_{i t r}+\sum_{k} \beta_{k} H_{i t k}+\sum_{y} \delta_{y} Y_{i t y}+\sum_{l} \varphi_{l} L_{i t l}+\varepsilon_{i t}
\end{aligned}
$$

where $i$ indexes the apartment unit, with $i=1, \ldots N$, and $t$ is the time in which a transaction takes place, with $t=1, \ldots T$. $P$ is an $(N \times 1)$ vector of transaction prices of apartment units, where $N$ is the total number of observations. $D$ is an $(N \times 1)$ vector of the linear distances between each property and the project site and $R$ is an $(N \times r)$ matrix of radius ring distance dummies where $r$ is the number of the dummies. $H$ is an $(N \times k)$ matrix of hedonic variables accounting for property characteristics where $k$ is the number of the variables. $Y$ is an $(N \times y)$ matrix containing yearly time dummies and $L$ is an $(N \times l)$ matrix containing location dummies where $y$ and $l$ are the number of the time dummies and the number of the location dummies respectively. $\varepsilon$ is an $(N \times 1)$ vector of independently and identically distributed error terms.

The main coefficients of interest are the ones associated with the price effect due to the proximity to the project site. The first one in Equation (1), $\alpha$, is associated with the linear effect which estimates the marginal effect as being further away from the project site by one kilometre. The second one in Equation (2), $\gamma$, is a $(r \times 1)$ vector of coefficients associated with the non-linear effects which estimate the value of apartment prices in the impact area (Ring0.5 - Ring3 respectively), compared to the control area (Ring 3.5). $\beta, \delta$ and $\varphi$ are a $(k \times 1),(y \times 1)$ and $(l \times 1)$ vector of coefficients associated with hedonic variables $(H)$, time dummy variables $(Y)$ and location dummy variables $(L)$ respectively. We use a semi-logarithm form which is widely used in a hedonic house price model as it allows the value added to vary proportionally with the characteristics of the property and the coefficient estimated has intuitively simple interpretation (i.e. as a measure of elasticity) (Malpezzi, 2003).

In a hedonic price modelling, it is widely accepted that a portion of the unexplained variance of the price is related to spatial relations among properties (Anselin, 1988; Can, 1992; LeSage and Pace, 2009). With regard to the spatial transmission of the announcement effect, sellers who observe an increase in apartment prices in proximity to the project site following the development announcement, may ask for the same premium (Case and Shiller, 2003; LeSage and Pace, 2009). In order to capture 
the spatial autoregressive effect, we extend the baseline hedonic model by a spatio-temporal autoregressive term, formalising a spatio-temporal autoregressive model (STAR) ${ }^{14}$ as follows:

$\log \left(P_{i t}\right)=c+\rho W P_{i t}+\alpha D_{i t}+\sum_{k} \beta_{k} H_{i t k}+\sum_{y} \delta_{y} Y_{i t y}+\sum_{l} \varphi_{l} L_{i t l}+\varepsilon_{i t}$
$\log \left(P_{i t}\right)=c+\rho W P_{i t}+\sum_{r} \gamma_{r} R_{i t r}+\sum_{k} \beta_{k} H_{i t k}+\sum_{y} \delta_{y} Y_{i t y}+\sum_{l} \varphi_{l} L_{i t l}+\varepsilon_{i t}$

where $W$ is an $(N \times N)$ exogenous spatio-temporal weight matrix, in which each element corresponds to a spatio-temporal weight based on the spatial and temporal distances between each pair of properties. The spatio-temporal weight matrix is multiplied by a vector of house prices, producing the interaction term $W P_{i t}$ of dimension $(N \times 1)$. The interaction term expresses the mean price of neighbouring apartments specified by the spatio-temporal weight matrix $W$. The spatial coefficient $\rho$ measures the correlation between a house price and average price of its neighbouring houses, that is spatial autoregressive effect of the mean growth of neighbouring house prices on the own transaction price (Dubé and Legros, 2014; LeSage and Pace, 2009; Thanos et al., 2015). The construction of the spatial weight matrix $W$ is based on unidirectional temporal causality to make sure that the spatial autoregressive process only occurs from recently sold properties to future sales and not vice versa ${ }^{15}$.

\section{Time varying announcement effect}

In the second step, we identify the announcement effect over time. The STAR is extended to incorporate an additional interaction term that is the product of a distance variable with a time dummy variable. The extended model is as follows:

$$
\begin{aligned}
\log \left(P_{i t}\right)= & c+\rho W P_{i t}+\alpha D_{i t}+\sum_{y} \tau_{y}\left(D_{i t} \times Y_{i t y}\right)+\sum_{k} \beta_{k} H_{i t k}+\sum_{y} \delta_{y} Y_{i t y}+\sum_{l} \varphi_{l} L_{i t l}+\varepsilon_{i t} \\
\log \left(P_{i t}\right)= & c+\rho W P_{i t}+\sum_{r} \gamma_{r} R_{i t r}+\sum_{r y} \varphi_{r y}\left(R_{i t r} \times Y_{i t y}\right)+\sum_{k} \beta_{k} H_{i t k}+\sum_{y} \delta_{y} Y_{i t y}+\sum_{l} \varphi_{l} L_{i t l}+ \\
& \varepsilon_{i t}
\end{aligned}
$$

where $\left(D_{i t} \times Y_{i t y}\right)$ is an $(N \times y)$ matrix of the product of the linear distance and the time dummy for each property. $\left(R_{i t r} \times Y_{i t y}\right)$ is a $(N \times(r \times y))$ matrix of the product of a ring dummy and a time dummy for each property. The coefficients $\tau$ and $\varphi$, which are a $(y \times 1)$ vector and a $((r \times y) \times 1)$ vector, quantify the announcement effect each year. With the coefficients, we effectively examine the price

\footnotetext{
${ }^{14}$ The DID estimator allows not only to eliminate the problems related to the unobserved variables that affect a house price by comparing changes in house prices over time (Ahlfeldt and Kavetsos, 2014; Pope and Pope, 2015) but also to control for the remaining spatial autocorrelation among the error terms when it is not correlated with the independent variables (Dubé et al., 2014). In addition, as the main aim of this study is to control for possible spatial autoregressive effects of nearby housing values changes, the spatio-temporal autoregressive model is more suitable than the spatio-temporal error model (McMillen, 2010)

${ }^{15}$ See Appendix.
} 
effect associated with the proximity to the project site over time (Ahlfeldt and Kavetsos, 2014; Immergluck, 2009; McMillen and McDonald, 2004).

\section{Spatial difference-indifferences (SDID)}

In the third step, we include a DID interaction term as follows:

$$
\log \left(P_{i t}\right)=c+\rho W P_{i t}+\alpha D_{i t}+\eta P A_{i t}+\theta\left(D_{i t} \times P A_{i t}\right)+\sum_{k} \beta_{k} H_{i t k}+\sum_{y} \delta_{y} Y_{i t y}+\sum_{l} \varphi_{l} L_{i t l}+\varepsilon_{i t}
$$

$$
\begin{aligned}
\log \left(P_{i t}\right)= & c+\rho W P_{i t}+\sum_{r} \gamma_{r} R_{i t r}+\eta P A_{i t}+\sum_{r} \psi_{r}\left(R_{i t r} \times P A_{i t}\right)+\sum_{k} \beta_{k} H_{i t k}+\sum_{y} \delta_{y} Y_{i t y}+ \\
& \sum_{l} \varphi_{l} L_{i t l}+\varepsilon_{i t}
\end{aligned}
$$

where $P A$ is an $(N \times 1)$ vector of post-announcement dummy variables which equal to 1 if the transaction has taken place after an announcement related to the development and 0 otherwise. There are two relevant announcements - 1) the development announcement and 2) the cancellation announcement. $\theta$ is the SDID estimator of the linear announcement effect which reflects changes in average apartment prices with an increase in the distance from the project site by one kilometre following an announcement. A negative sign of this coefficient indicates a positive price effect with regard to the proximity to the project site. $\psi$ is a $(r \times 1)$ vector of coefficients associated with the nonlinear announcement effect which reflects changes in average apartment prices within the impact area following an announcement, compared to the control area. One of the important assumptions for the DID analysis is that the remaining coefficients remain constant over time (Case and Shiller, 1989; Dubé et al., 2014). Hence:

$$
\begin{aligned}
\theta= & {\left[\log \left(P_{\text {iafter-announcement }}\right)-\log \left(P_{\text {ibefore-announcement }}\right)\right] D_{i} } \\
\psi= & {\left[\log \left(P_{\text {impactafter-announcement }}\right)-\log \left(P_{\text {impcatbefore-announcement }}\right)\right]-} \\
& {\left[\log \left(P_{\text {controlafter-announcement }}\right)-\log \left(P_{\text {controlbefore-announcement }}\right)\right] }
\end{aligned}
$$

where impact is a radius ring dummy variable in the impact area and control in the control area.

The general DID estimator quantifies the announcement effect over time and across space while controlling for other effects that remain fixed over time, thereby eliminates the omitted variable problem (Gibbons and Machin, 2005; Pope and Pope, 2015). Moreover, the DID estimator has advantages of controlling for the spatial autocorrelation in the error terms which is not correlated with the explanatory variables (Dubé et al., 2014). By incorporating the DID term into the STAR model, we control for the possible spatial autocorrelation in house prices as well. The SDID specification statistically expresses the transaction price as a function of the announcement effect, the mean growth of the transaction prices in a neighbourhood and a set of hedonic variables, while adequately controlling for temporal and locational heterogeneity. For comparison, the DID estimators are applied into the baseline hedonic price model as follows: 


$$
\begin{aligned}
& \log \left(P_{i t}\right)=c+\alpha D_{i t}+\eta P A_{i t}+\theta\left(D_{i t} \times P A_{i t}\right)+\sum_{k} \beta_{k} H_{i t k}+\sum_{y} \delta_{y} Y_{i t y}+\sum_{l} \varphi_{l} L_{i t l}+\varepsilon_{i t} \\
& \log \left(P_{i t}\right)=c+\sum_{r} \gamma_{r} R_{i t r}+\eta P A_{i t}+\sum_{r} \psi_{r}\left(R_{i t r} \times P A_{i t}\right)+\sum_{k} \beta_{k} H_{i t k}+\sum_{y} \delta_{y} Y_{i t y}+\sum_{l} \varphi_{l} L_{i t l}+\varepsilon_{i t}
\end{aligned}
$$

\section{Empirical results}

The HPM and STAR model are operationalised with controls for all the variables respectively, and the results for the entire study period are presented in Table 2. Column (1) and (2) indicate regression results with the linear distance effect and Column (3) and (4) with the non-linear radius ring distance effect. All specifications have a reasonable prediction power and show the expected signs for the hedonic variables. The price of an apartment unit is positively correlated with size, rooms, bathrooms and parking space, floor level and proximity to a subway station. As well, the transaction price of an apartment within a larger complex in terms of number of apartment buildings and which is built by one of the major developers is also significantly higher. We observe that if the apartment is located in a building where some of the units have a status of social housing, the price of that apartment will be lower all else being equal. The strongest effect on the price of an apartment unit is the building permission for reconstruction, reflecting expected capital gains after reconstruction (Lee et al., 2005). We find that the older the apartment, the higher the price. Furthermore, the price of an apartment in a block built by a public construction company is higher.

The STAR model yields an estimate for rho $(\rho)$ of 0.128 and 0.120 for the linear and non-linear distance specifications respectively. Both are significant at the $99 \%$ level. This result suggests significant spatial autocorrelation in house prices. For example, if there is a $\$ 10,000$ increase in average prices of neighbouring apartments located within $3.5 \mathrm{~km}$ from the property during the past 12 months, it would lead to an increase of $\$ 1,200-\$ 1,280$ in the respective unit. Accounting for the spatial autoregressive effect improves the model fit in terms of lower value of the Akaike information criterion (AIC) and the Bayesian information criterion (BIC), as compared to the HPM. Another important difference between the STAR and HPM is in the coefficients of the proximity associated with the project site. Capturing the spatial autoregressive effect in transaction prices produces different estimation in terms of the magnitude as well as sign and statistical significance, suggesting that ignoring the information regarding the spatial autocorrelation would lead to an inappropriate model specification. Given the significant spatial autoregressive effect, we focus on the results by the STAR.

For the linear distance in the STAR model (Column (2)), we show that proximity to the development site is associated with an increase in apartment prices. Moving one kilometre away from the development reduced apartment prices by $1.1 \%$. The results with radius ring distance (Column (4)) are roughly in line with this pattern. Apartments in the impact area sell at a higher price than the those in the control area (only except for Ring3) by up to 7.6\%, and the gap between the two areas tends to 
Table 2

Regression results for the HPM and STAR

\begin{tabular}{|c|c|c|c|c|}
\hline \multirow{2}{*}{ VARIABLES } & (1) HPM & (2) STAR & (3) HPM & (4) STAR \\
\hline & Equation (1) & Equation (3) & Equation (2) & Equation (4) \\
\hline \multirow[t]{2}{*}{ Size } & $0.003 * * *$ & $0.002 * * *$ & $0.003 * * *$ & $0.002 * * *$ \\
\hline & $(0.000)$ & $(0.000)$ & $(0.000)$ & $(0.000)$ \\
\hline \multirow[t]{2}{*}{ Floor } & $0.003 * * *$ & $0.002 * * *$ & $0.003 * * *$ & $0.002 * * *$ \\
\hline & $(0.000)$ & $(0.000)$ & $(0.000)$ & $(0.000)$ \\
\hline \multirow[t]{2}{*}{ Rooms } & $0.025 * * *$ & $0.013 * * *$ & $0.022 * * *$ & $0.012 * * *$ \\
\hline & $(0.002)$ & $(0.001)$ & $(0.002)$ & $(0.001)$ \\
\hline \multirow[t]{2}{*}{ Bathrooms } & $0.060 * * *$ & $0.027 * * *$ & $0.059 * * *$ & $0.027 * * *$ \\
\hline & $(0.002)$ & $(0.001)$ & $(0.002)$ & $(0.001)$ \\
\hline \multirow[t]{2}{*}{ Age } & $0.005^{* * *}$ & $0.002 * * *$ & $0.005^{* * *}$ & $0.002 * * *$ \\
\hline & $(0.000)$ & $(0.000)$ & $(0.000)$ & $(0.000)$ \\
\hline \multirow[t]{2}{*}{ Age squared } & $-0.000 * * *$ & $-0.000 * * *$ & $-0.000 * * *$ & $-0.000 * * *$ \\
\hline & $(0.000)$ & $(0.000)$ & $(0.000)$ & $(0.000)$ \\
\hline \multirow[t]{2}{*}{ Buildings } & $0.009 * * *$ & $0.004 * * *$ & $0.009 * * *$ & $0.004 * * *$ \\
\hline & $(0.000)$ & $(0.000)$ & $(0.000)$ & $(0.000)$ \\
\hline \multirow[t]{2}{*}{ Units } & $-0.000 * * *$ & $-0.000 * * *$ & $-0.000 * * *$ & $-0.000 * * *$ \\
\hline & $(0.000)$ & $(0.000)$ & $(0.000)$ & $(0.000)$ \\
\hline \multirow[t]{2}{*}{ Parking } & $0.031 * * *$ & $0.015 * * *$ & $0.027 * * *$ & $0.012 * * *$ \\
\hline & $(0.001)$ & $(0.001)$ & $(0.001)$ & $(0.001)$ \\
\hline \multirow[t]{2}{*}{ Heating $^{+}$} & $0.035 * * *$ & $0.018 * * *$ & $0.037 * * *$ & $0.019 * * *$ \\
\hline & $(0.002)$ & $(0.002)$ & $(0.002)$ & $(0.002)$ \\
\hline \multirow[t]{2}{*}{ Complex $^{+}$} & $0.031 * * *$ & $0.021 * * *$ & $0.036^{* * * *}$ & $0.028 * * *$ \\
\hline & $(0.002)$ & $(0.002)$ & $(0.002)$ & $(0.002)$ \\
\hline \multirow[t]{2}{*}{ Subway } & $-0.000 * * *$ & $-0.000 * * *$ & $-0.000 * * *$ & $-0.000 * * *$ \\
\hline & $(0.000)$ & $(0.000)$ & $(0.000)$ & $(0.000)$ \\
\hline \multirow[t]{2}{*}{ Reputation $^{+}$} & $0.023 * * *$ & $0.011 * * *$ & $0.026 * * *$ & $0.012 * * *$ \\
\hline & $(0.002)$ & $(0.001)$ & $(0.002)$ & $(0.001)$ \\
\hline \multirow[t]{2}{*}{ Public company $^{+}$} & $0.060 * * *$ & $0.047 * * *$ & $0.032 * * *$ & $0.036 * * *$ \\
\hline & $(0.006)$ & $(0.005)$ & $(0.007)$ & $(0.005)$ \\
\hline \multirow[t]{2}{*}{ Low-rental $^{+}$} & $-0.055^{* * *}$ & $-0.021 * * *$ & $-0.027 * * *$ & -0.003 \\
\hline & $(0.004)$ & $(0.003)$ & $(0.004)$ & $(0.004)$ \\
\hline \multirow[t]{2}{*}{ Permission $^{+}$} & $0.096 * * *$ & $0.066 * * *$ & $0.100 * * *$ & $0.065^{* * *}$ \\
\hline & $(0.005)$ & $(0.004)$ & $(0.005)$ & $(0.004)$ \\
\hline \multirow[t]{2}{*}{ Distance } & $0.011 * * *$ & $-0.011 * * *$ & & \\
\hline & $(0.002)$ & $(0.002)$ & & \\
\hline \multirow[t]{2}{*}{ Ring0.5 $5^{+}$} & & & $0.025 * * *$ & $0.076 * * *$ \\
\hline & & & $(0.008)$ & $(0.006)$ \\
\hline \multirow[t]{2}{*}{ Ring $1^{+}$} & & & $-0.021 * * *$ & $0.033 * * *$ \\
\hline & & & $(0.006)$ & $(0.005)$ \\
\hline \multirow[t]{2}{*}{ Ring1.5+ } & & & 0.002 & $0.030 * * *$ \\
\hline & & & $(0.006)$ & $(0.005)$ \\
\hline \multirow[t]{2}{*}{ Ring $2^{+}$} & & & $0.022 * * *$ & $0.041 * * *$ \\
\hline & & & $(0.006)$ & $(0.005)$ \\
\hline \multirow[t]{2}{*}{ Ring $2.5^{+}$} & & & -0.002 & $0.021 * * *$ \\
\hline & & & $(0.005)$ & $(0.004)$ \\
\hline Ring $3^{+}$ & & & $-0.041^{* * *}$ & $-0.014 * * *$ \\
\hline
\end{tabular}




\begin{tabular}{|c|c|c|c|c|}
\hline \multirow{2}{*}{ VARIABLES } & (1) HPM & (2) STAR & (3) HPM & (4) STAR \\
\hline & Equation (1) & Equation (3) & Equation (2) & Equation (4) \\
\hline & & & $(0.003)$ & $(0.003)$ \\
\hline \multirow[t]{2}{*}{ Rho $(\rho)$} & & $0.128 * * *$ & & $0.120 * * *$ \\
\hline & & $(0.006)$ & & $(0.006)$ \\
\hline \multirow[t]{2}{*}{ Constant } & $8.032 * * *$ & $6.912 * * *$ & $8.109 * * *$ & $6.970 * * *$ \\
\hline & $(0.028)$ & $(0.056)$ & $(0.028)$ & $(0.057)$ \\
\hline Time fixed effect & Yes & Yes & Yes & Yes \\
\hline Location fixed effect & Yes & Yes & Yes & Yes \\
\hline $\operatorname{Adj}-R^{2}$ & 0.893 & 0.927 & 0.895 & 0.928 \\
\hline Log-likelihood & & 28134.782 & & 28476.823 \\
\hline AIC & -50178.923 & -56133.564 & -50591.576 & -56805.646 \\
\hline $\mathrm{BIC}$ & -48719.344 & -55592.165 & -49092.188 & -56216.476 \\
\hline Observations & 21,200 & 21,200 & 21,200 & 21,200 \\
\hline \multicolumn{5}{|c|}{ Standard errors in parentheses $* * * \mathrm{p}<0.01, * * \mathrm{p}<0.05, * \mathrm{p}<0.1$} \\
\hline
\end{tabular}

Note: 1$)^{+}$dummy variable.

2) A coefficient of dummy variable indicates an effect in percentage based on [exp (coefficient)-1] by Halvorsen and Palmquist (1980).

diminish with an increase in the distance from the project site. In particular, apartments within $0.5 \mathrm{~km}$ from the project site sell at a premium of $7.3 \%$ on average all else equal than those located the control area, which is $3-3.5 \mathrm{~km}$ away from the project site. Thus, properties in direct proximity will experience the strongest effect of the announcement. Overall, the results suggest a positive relationship between apartment prices and proximity to the project site.

Next, we split the study period based on the two announcements into three sub-periods, a predevelopment announcement period (pre-DA), a post-development and pre-cancellation announcement period (post-DA), and a post-cancellation announcement period (post-CA). The post-DA spans from August 2007 to March 2013. Due to data availability, the pre-DA covers 19 months from January 2006 to July 2007 whereas the post-CA covers 33 months from April 2013 to December 2015. Summary statistics of apartment transactions in the three periods are presented in Table 3 . The average transaction price for the post-DA as well as for the post-CA is higher than for the pre-DA although other property and locational characteristics do not differ across the sub-periods. For the pre-DA (Column (1) and (2) in Table 4), the coefficients suggest that apartment prices near the project site were already higher than comparable properties located further away from the project site before the development announcement. If the spatial effects on the apartment value are not considered, the estimation of the announcement effect will be biased. The results for the post-DA (Column (3) and (4) in Table 4) can be interpreted as the announcement effects. Following the development announcement, apartment prices decrease by $1.5 \%$ when moving $1 \mathrm{~km}$ away from the project site.

With ring distances, apartments in the impact area sell at a premium by up to $10.7 \%$ relative to comparable apartments in the control area. However, given the existing premium during the pre-DA 
Table 3

Descriptive statistics of variables

\begin{tabular}{|c|c|c|c|c|c|c|}
\hline \multirow{2}{*}{ Variable } & \multicolumn{2}{|c|}{ Pre-DA $(\mathrm{N}=5,489)$} & \multicolumn{2}{|c|}{ Post-DA $(\mathrm{N}=8,949)$} & \multicolumn{2}{|c|}{ Post-CA $(\mathrm{N}=6,762)$} \\
\hline & Mean & Std. Dev. & Mean & Std. Dev. & Mean & Std. Dev. \\
\hline Price (USD) & 457,399 & 306,086 & 554,725 & 334,891 & 513,582 & 244,581 \\
\hline Size $\left(\mathrm{m}^{2}\right)$ & 83.752 & 31.763 & 83.689 & 35.804 & 84.632 & 31.584 \\
\hline Floor & 9.216 & 5.929 & 9.982 & 6.279 & 9.730 & 6.057 \\
\hline Rooms & 3.123 & 0.627 & 3.095 & 0.724 & 3.135 & 0.647 \\
\hline Bathrooms & 1.567 & 0.509 & 1.605 & 0.505 & 1.609 & 0.497 \\
\hline Age & 9.228 & 8.366 & 11.906 & 8.461 & 17.154 & 8.411 \\
\hline Age squared & 155.139 & 297.730 & 213.319 & 342.658 & 364.975 & 421.623 \\
\hline Buildings & 8.060 & 5.556 & 8.310 & 5.719 & 8.383 & 5.416 \\
\hline Units & 704.701 & 560.666 & 727.629 & 560.137 & 728.199 & 545.105 \\
\hline Parking & 1.116 & 0.444 & 1.171 & 0.550 & 1.127 & 0.554 \\
\hline Heating $^{+}$ & 0.382 & 0.486 & 0.403 & 0.490 & 0.403 & 0.531 \\
\hline Complex $^{+}$ & 0.794 & 0.404 & 0.779 & 0.415 & 0.817 & 0.387 \\
\hline Subway & 494.065 & 244.647 & 411.686 & 223.589 & 447.009 & 229.661 \\
\hline Reputation $^{+}$ & 0.521 & 0.500 & 0.552 & 0.497 & 0.574 & 0.495 \\
\hline Public Company $^{+}$ & 0.011 & 0.102 & 0.016 & 0.127 & 0.013 & 0.113 \\
\hline Low-rental $^{+}$ & 0.079 & 0.269 & 0.074 & 0.262 & 0.082 & 0.275 \\
\hline Permission $^{+}$ & 0.029 & 0.168 & 0.027 & 0.161 & 0.028 & 0.166 \\
\hline Distance & 1.829 & 0.809 & 1.991 & 0.751 & 1.929 & 0.765 \\
\hline Ring $0.5^{+}$ & 0.024 & 0.153 & 0.007 & 0.083 & 0.015 & 0.122 \\
\hline Ring $1^{+}$ & 0.131 & 0.337 & 0.060 & 0.238 & 0.078 & 0.268 \\
\hline $\operatorname{Ring} 1.5^{+}$ & 0.263 & 0.440 & 0.245 & 0.430 & 0.260 & 0.439 \\
\hline Ring $2^{+}$ & 0.142 & 0.349 & 0.188 & 0.391 & 0.169 & 0.374 \\
\hline Ring $2.5^{+}$ & 0.227 & 0.419 & 0.264 & 0.441 & 0.260 & 0.439 \\
\hline Ring $3^{+}$ & 0.128 & 0.334 & 0.117 & 0.322 & 0.118 & 0.323 \\
\hline Ring $3.5^{+}$ & 0.086 & 0.280 & 0.118 & 0.323 & 0.100 & 0.300 \\
\hline
\end{tabular}

Note: ${ }^{+}$dummy variable.

period, the announcement effect may be overestimated. The positive relationship between the apartment price and the proximity to the project site remains even after the project is cancelled (Column (5) and (6) in Table 4). The results are intuitively implausible. Given the significant positive effects of the proximity to the project site for the post-DA, we should expect to observe negative effects for the postCA period. Those results may suggest that a simple hedonic analysis that only reflects differences in the price level, but not in price changes, may not account for the casual linkage between the price changes and the project precisely, hence produce biased estimates for the announcement effect (Gibbons and Machin, 2005).

Through comparison of coefficients over the three periods, the announcement effect can be inferred indirectly. For example, compared to the pre-DA, the higher coefficients for the post-DA and the lower coefficients for the post-CA can be clues for the existence of a positive development 
Table 4

Summary of regression results according to the phase of the project

\begin{tabular}{|c|c|c|c|c|c|c|}
\hline \multirow{2}{*}{ VARIABLES } & \multicolumn{2}{|c|}{ Pre-DA } & \multicolumn{2}{|c|}{ Post-DA } & \multicolumn{2}{|c|}{ Post-CA } \\
\hline & Equation (3) & Equation (4) & Equation (3) & Equation (4) & Equation (3) & Equation (4) \\
\hline \multirow[t]{2}{*}{ Distance } & $-0.006^{*}$ & & $-0.015 * * *$ & & -0.002 & \\
\hline & $(0.004)$ & & $(0.002)$ & & $(0.002)$ & \\
\hline \multirow[t]{2}{*}{ Ring0.5 } & & $0.084 * * *$ & & $0.107 * * *$ & & $0.053 * * *$ \\
\hline & & $(0.014)$ & & $(0.012)$ & & $(0.008)$ \\
\hline \multirow[t]{2}{*}{ Ring1 } & & 0.006 & & $0.057 * * *$ & & $0.024 * * *$ \\
\hline & & $(0.012)$ & & $(0.008)$ & & $(0.006)$ \\
\hline \multirow[t]{2}{*}{ Ring1.5 } & & $0.038 * * *$ & & $0.040 * * *$ & & $0.025 * * *$ \\
\hline & & $(0.011)$ & & $(0.007)$ & & $(0.006)$ \\
\hline \multirow[t]{2}{*}{ Ring2 } & & $0.042 * * *$ & & $0.054 * * *$ & & $0.041 * * *$ \\
\hline & & $(0.011)$ & & $(0.007)$ & & $(0.006)$ \\
\hline \multirow[t]{2}{*}{ Ring2.5 } & & 0.013 & & $0.027 * * *$ & & $0.023 * * *$ \\
\hline & & $(0.010)$ & & $(0.006)$ & & $(0.005)$ \\
\hline \multirow[t]{2}{*}{ Ring3 } & & $-0.033 * * *$ & & $-0.016 * * *$ & & $-0.013 * * *$ \\
\hline & & $(0.007)$ & & $(0.005)$ & & $(0.004)$ \\
\hline Ring3.5 & & Reference & & Reference & & Reference \\
\hline \multirow[t]{2}{*}{ Rho $(\rho)$} & $0.102 * * *$ & $0.109 * * *$ & $0.138 * * *$ & $0.131 * * *$ & $0.134 * * *$ & $0.122 * * *$ \\
\hline & $(0.015)$ & $(0.014)$ & $(0.009)$ & $(0.009)$ & $(0.011)$ & $(0.011)$ \\
\hline Hedonic controls & Yes & Yes & Yes & Yes & Yes & Yes \\
\hline \multirow{2}{*}{$\begin{array}{l}\text { Time fixed effect } \\
\text { Location fixed } \\
\text { effect }\end{array}$} & Yes & Yes & Yes & Yes & Yes & Yes \\
\hline & Yes & Yes & Yes & Yes & Yes & Yes \\
\hline $\operatorname{Adj}-R^{2}$ & 0.917 & 0.919 & 0.942 & 0.943 & 0.941 & 0.942 \\
\hline Log-likelihood & 6453.138 & 6542.595 & 12940.726 & 13047.177 & 11573.352 & 11685.823 \\
\hline AIC & -12790.276 & -12959.190 & -25749.452 & -25952.354 & -23014.704 & -23175.645 \\
\hline $\mathrm{BIC}$ & -12457.805 & -12593.942 & -24379.042 & -24546.543 & -18130.500 & -18257.467 \\
\hline Observations & 5,489 & 5,489 & 8,949 & 8,949 & 6,762 & 6,762 \\
\hline
\end{tabular}

Note: A coefficient of ring distance (dummy variable) indicates an effect in percentage based on [exp (coefficient)-1] by Halvorsen and Palmquist (1980).

announcement effect and a negative cancellation announcement effect respectively. In order to examine the announcement effect more directly and precisely, we conduct the DID analysis.

\section{Time varying announcement effects}

Fig. 2 and 3 plot the transaction price premium associated with the proximity to the project site throughout the study period. The vertical axis in Fig. 2 and 3 corresponds to the value of $\tau$ in Equation (5) and $\varphi$ in Equation (6) respectively, which captures the interaction term of distance (linear and rings) and yearly dummies. Fig. 2 uses the linear distance to the site and shows a sharp increase in apartment prices in 2007. After peaking in 2008, the premium gradually decreases but stays positive until 2014. The time varying effect using the ring distance in Fig. 3 illustrates a similar pattern. An increase in apartment prices is observed in all impact areas in 2007 relative to the control area. The price premium in the impact areas gradually decreases after peaking in 2008, then stays high in the first two rings but disappears in the rest of the impact areas. The price levels in all impact areas reach a trough in 2014. Fig. 3 suggests a spatially diminishing price premium pattern across all periods. 
Fig. 2. Linear distance time varying effect

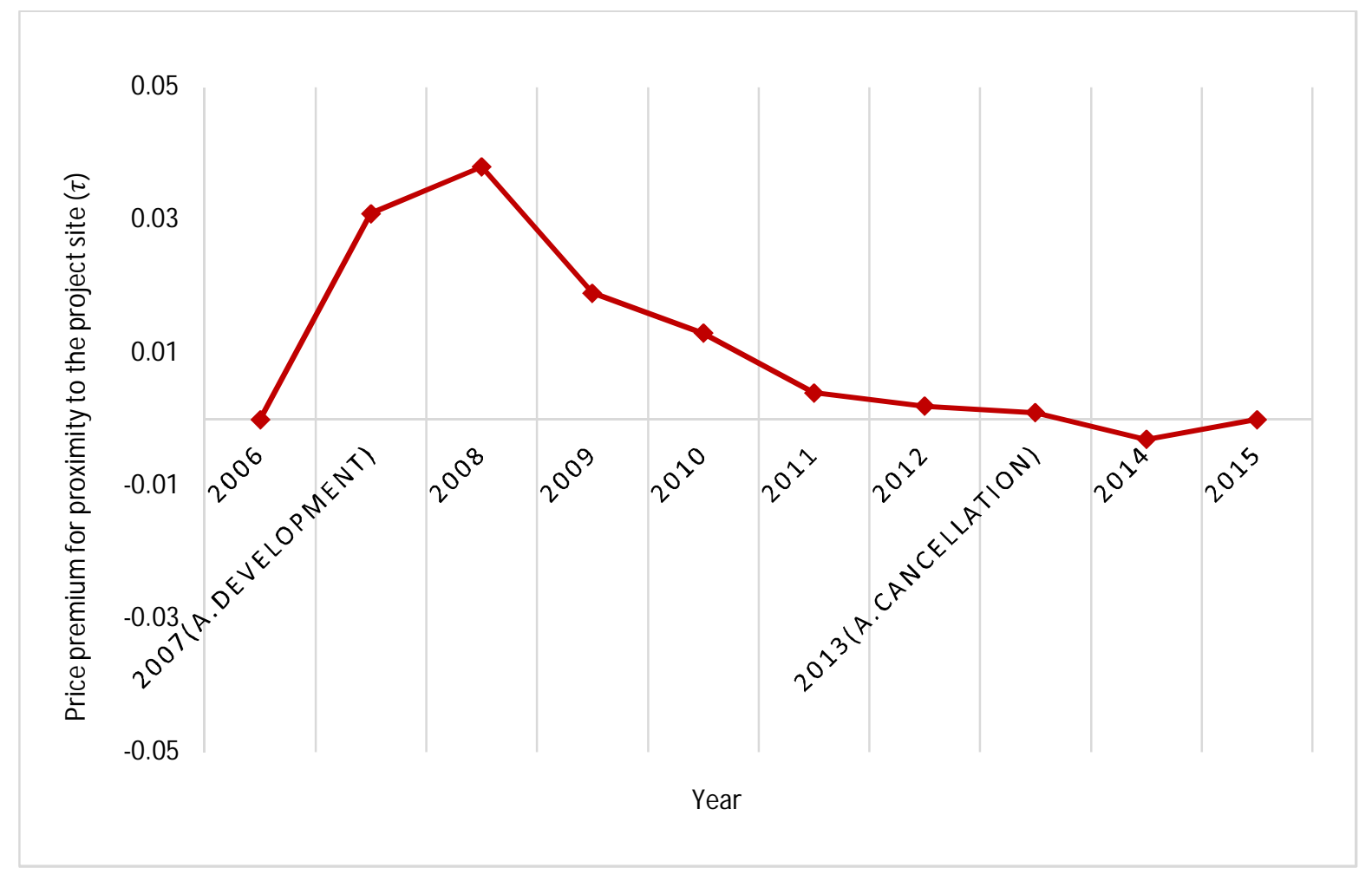

Note: The estimated coefficients are multiplied by -1 so that an increase in index reveals a positive proximity effect capitalising in apartment prices.

Fig. 3. Radius ring distance time varying effect

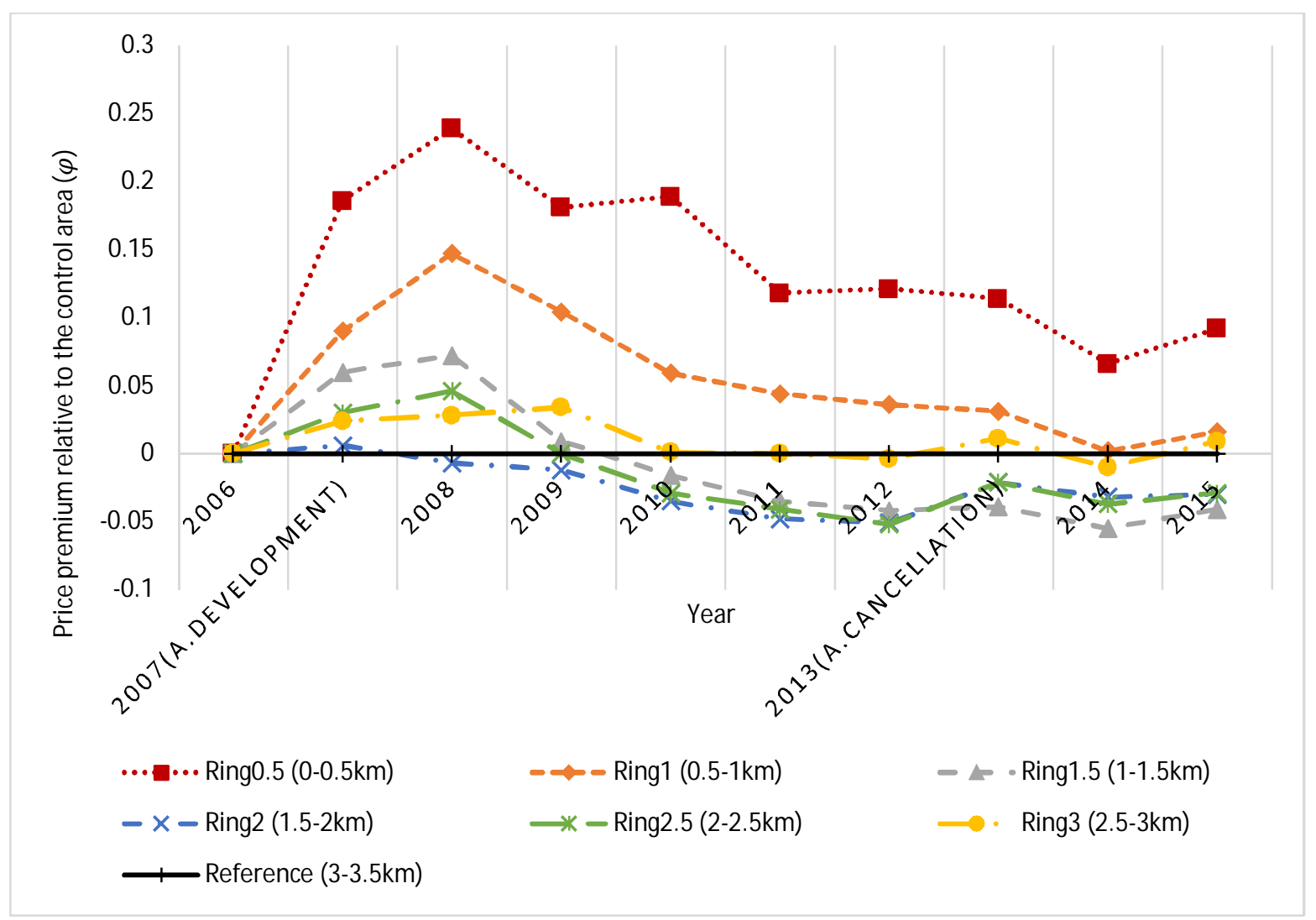


Both figures represent plausible market reactions in light of the timeline of the announcement of the development (August 2007) and its cancellation (April 2013). Those results suggest that the housing market responds shortly after the information is released and keeps the momentum until the cancellation with the price premium gradually vanishing in each period. We can see that the announcement effects tend to intensify one year after the announcement is made although a strong contemporary effect is also observed. This suggest that albeit the lag in house price responses, the market in Seoul appears to be relatively efficient.

\section{Spatial difference-in-differences estimates for the announcement effect}

A DID approach is applied to the HPM (HDID) and STAR (SDID) respectively using two pooled datasets: 1) from the pre-DA to the post-DA and 2) from the post-DA to the post-CA. Table 5 shows the results. The fit to the data is reasonable across all models, explaining over $90 \%$ of the variation. Most of the DID coefficients are statistically significant. First, we briefly compare the HDID and SDID. The results suggest a better fit for the SDID model and highlight the importance of considering spatial autoregressive effects in transaction prices. The SDID produces an estimation for rho $(\rho)$ of between 0.121 and 0.151 over all specifications which are statistically significant at the $99 \%$ level, indicating significant spatial autoregressive effects in apartment prices. Statistically, these suggest that using the HDID estimator can introduce bias in the coefficients as the spatial term affects the estimation of the marginal effects of the DID estimates (Dubé et al., 2014). The HDID estimators are generally higher than the SDID estimators, thus overestimating the announcement effects as the spatial autoregressive term is missing from the model.

The results of the SDID show the existence of a significant announcement effect, and the effect is highly associated with the proximity to the project site. The linear effect of the development announcement in Column (2) suggests that apartment prices decrease by $0.1 \%$ for each kilometre away from the project site. This means that apartment prices experience less of an increase when located further away from the project site, to be more exact, $0.1 \%$ less appreciation. The linear distance impact is economically small, but it is statistically significant. We see evidence of the existence of a positive development announcement effect within a $3.5 \mathrm{~km}$ radius area from the project site. We find more supporting evidence of the positive announcement effect using the ring distance measures (Column (4)). Apartments within $0.5 \mathrm{~km}$ from the project site sell at $7.3 \%$ higher price on average than those in the control area. Notably, this is the strongest announcement effect. Apartments located between $0.5-1 \mathrm{~km}$ experience a price boost of $2.4 \%$, compared to comparable apartments in the control area. The significant positive price effect dissipates beyond $1 \mathrm{~km}$ from the project site. On the contrary, we find that apartment prices between $1-2.5 \mathrm{~km}$ from the project site decrease by $2-3 \%$ compared to comparable apartments in the control area. These patterns suggest that the spatial variation of the announcement effect is not necessarily linear, which can explain why the overall distance effect is economically small. 
Table 5

Difference-in-differences estimates for the announcement effect

\begin{tabular}{|c|c|c|c|c|}
\hline \multirow{3}{*}{ VARIABLES } & \multicolumn{4}{|c|}{ The effect of development announcement } \\
\hline & (1) HDID & (2) SDID & (3) HDID & (4) SDID \\
\hline & Equation (11) & Equation (7) & Equation (12) & Equation $(\varepsilon$ \\
\hline D_Post-DA & $\begin{array}{l}-0.012 * * * \\
(0.002)\end{array}$ & $\begin{array}{l}-0.001 * * * \\
(0.002)\end{array}$ & & \\
\hline Ring0.5_Post-DA & & & $\begin{array}{l}0.131 \text { *** } \\
(0.013)\end{array}$ & $\begin{array}{l}0.073 * * * \\
(0.011)\end{array}$ \\
\hline Ring1_Post-DA & & & $\begin{array}{l}0.060^{* * * *} \\
(0.006)\end{array}$ & $\begin{array}{l}0.024 * * * \\
(0.005)\end{array}$ \\
\hline Ring1.5_Post-DA & & & $\begin{array}{l}-0.009^{*} \\
(0.005)\end{array}$ & $\begin{array}{l}-0.029 * * * \\
(0.004)\end{array}$ \\
\hline Ring2_ Post-DA & & & $\begin{array}{l}-0.024 * * * \\
(0.005)\end{array}$ & $\begin{array}{l}-0.024 * * * \\
(0.005)\end{array}$ \\
\hline Ring2.5_Post-DA & & & $\begin{array}{l}-0.017 * * * \\
(0.005)\end{array}$ & $\begin{array}{l}-0.021 * * * \\
(0.004)\end{array}$ \\
\hline Ring3_Post-DA & & & $\begin{array}{l}0.006 \\
(0.006)\end{array}$ & $\begin{array}{l}-0.000 \\
(0.005)\end{array}$ \\
\hline Ring3.5_Post-DA & & & Reference & Reference \\
\hline
\end{tabular}

D Post-CA

$\begin{array}{ll}0.023^{* * *} & 0.010 * * * \\ (0.001) & (0.001)\end{array}$

Ring 0.5 _ Post-CA

Ring1_Post-CA

Ring1.5_Post-CA

The effect of cancellation announcement

$\begin{array}{lll}\text { (6) SDID (7) HDID } & \text { (8) SDID }\end{array}$

Equation (11) $\quad$ Equation (7) $\quad$ Equation (12) $\quad$ Equation (8)

Ring2_ Post-CA

$\begin{array}{ll}-0.094 * * * & -0.052 * * * \\ (0.011) & (0.009) \\ -0.067 * * * & -0.035 * * * \\ (0.005) & (0.004) \\ -0.048 * * * & -0.015 * * * \\ (0.004) & (0.003) \\ -0.009 * * & 0.004 \\ (0.004) & (0.003)\end{array}$




\begin{tabular}{|c|c|c|c|c|c|c|c|c|}
\hline \multirow{3}{*}{ VARIABLES } & \multicolumn{4}{|c|}{ The effect of development announcement } & \multicolumn{4}{|c|}{ The effect of cancellation announcement } \\
\hline & (1) HDID & (2) SDID & (3) HDID & (4) SDID & (5) HDID & (6) SDID & (7) HDID & (8) SDID \\
\hline & Equation (11) & Equation (7) & Equation (12) & Equation (8) & Equation (11) & Equation (7) & Equation (12) & Equation (8) \\
\hline \multirow[t]{2}{*}{ Ring2.5_Post-CA } & & & & & & & $-0.022 * * *$ & -0.003 \\
\hline & & & & & & & $(0.004)$ & $(0.003)$ \\
\hline \multirow[t]{2}{*}{ Ring3_Post-CA } & & & & & & & $-0.011 * *$ & 0.000 \\
\hline & & & & & & & $(0.004)$ & $(0.004)$ \\
\hline Ring3.5_Post-CA & & & & & & & Reference & Reference \\
\hline \multirow[t]{2}{*}{ Rho $(\rho)$} & & $0.151 * * *$ & & $0.136^{* * * *}$ & & \multirow{2}{*}{\multicolumn{2}{|c|}{$\begin{array}{l}0.138 * * * \\
(0.007)\end{array}$}} & $0.121 * * *$ \\
\hline & & $(0.008)$ & & $(0.008)$ & & & & $(0.007)$ \\
\hline Hedonic controls & Yes & Yes & Yes & Yes & Yes & Yes & Yes & Yes \\
\hline Time fixed effect & Yes & Yes & Yes & Yes & Yes & Yes & Yes & Yes \\
\hline Location fixed effect & Yes & Yes & Yes & Yes & Yes & Yes & Yes & Yes \\
\hline Post-period dummy & Yes & Yes & Yes & Yes & Yes & Yes & Yes & Yes \\
\hline Linear effect & Yes & Yes & No & No & Yes & Yes & No & No \\
\hline Radius ring effect & No & No & Yes & Yes & No & No & Yes & Yes \\
\hline Adj- $R^{2}$ & 0.902 & 0.928 & 0.906 & 0.931 & 0.908 & 0.939 & 0.912 & 0.936 \\
\hline Log-likelihood & 16892.033 & 18517.181 & 17198.871 & 18675.283 & 21260.943 & 23029.055 & 21621.719 & 23178.197 \\
\hline AIC & -33652.065 & -36894.362 & -34245.742 & -37186.566 & -42391.885 & -45918.110 & -43093.438 & -46192.394 \\
\hline $\mathrm{BIC}$ & -32858.399 & -36363.929 & -33376.300 & -36565.201 & -36953.607 & -45381.762 & -37578.539 & -45564.100 \\
\hline Observations & 14,438 & 14,438 & 14,438 & 14,438 & 15,711 & 15,711 & 15,711 & 15,711 \\
\hline
\end{tabular}

Note: A coefficient of ring distance (dummy variable) indicates an effect in percentage based on [exp (coefficient)-1] by Halvorsen and Palmquist (1980). 
Such non-linear pattern demonstrates that a general equilibrium process can be in place which offsets the increase in prices near the project site (within $1 \mathrm{~km}$ ) by a decline in prices in more distant areas (1$2.5 \mathrm{~km}$ ) (Boyce et al., 1972). There seem to be a substantial shift in the demand concentrated only in properties in direct proximity as triggered by the anticipation about future housing value growth around the project area.

Next we estimate the cancellation announcement effect (Column (6) and Column (8)). For this measurement, we compare apartment prices between the post-DA and the post-CA. The results show the expected negative impact of the cancellation announcement on apartment prices. The linear distance effect following the cancellation announcement (Column (6)) is positive indicating that apartment prices tend to increase when located further away from the project site. That is, apartments experience less of a decrease in transaction prices by locating further away from the project, to be more exact, $1 \%$ less reduction after the cancellation announcement. The negative cancellation announcement effects based on the ring distances (Column (8)) show roughly linear patterns, gradually diminishing with an increase in the distance from the project site. Similar to the response following the development announcement, properties in the closest radius ring (within $0.5 \mathrm{~km}$ ) are most strongly influenced by the cancellation announcement, decreasing in price by $5.2 \%$ compared to comparable apartments in the control area. Apartments located $0.5-1 \mathrm{~km}$ and $1-1.5 \mathrm{~km}$ from the project site also experience a price decline by $3.5 \%$ and $1.5 \%$ respectively. No significant price changes are observed beyond $1.5 \mathrm{~km}$ from the project site.

Overall, we find compelling evidence of significant announcement effects using two different SDID time frameworks. The announcements related to the development are enough to have a significant impact on the local housing market. Apartments surrounding the project site experience a significant increase in their prices after the development announcement, but a substantial portion of the premium is removed by the cancellation announcement. This pattern is most evident in the closest ring, within $0.5 \mathrm{~km}$ from the project site, showing spatially diminishing announcement effects when locating further away. We find a net positive announcement effect of $2.1 \%$. This suggests that the announcements have overall a positive signalling effect of what the fair value of apartments should be in this area. There can be residual expectations about an alternative project which can be down-sized. As a matter of fact, the need for an alternative development has been continuously raised since the cancellation of the project to minimise the aftereffect on the economy of the region. The positive gap of $2.1 \%$ may reflect the remaining expectation about any alternative development in this area.

The spatial variation of the announcement effects is quite clear. Apartments within $1 \mathrm{~km}$ from the project site experience a boom and a bust following the development and cancellation announcements respectively. Apartment in $1-1.5 \mathrm{~km}$, however, suffer decrease in prices after the development announcement, and again experience depreciation following the cancellation 
announcement. Such spatial pattern of price effects implies that housing demand would substantially move for the benefits of accessibility to the new amenities by the perceptions about expected positive externalities such as the capital gain from housing value growth and the consumption benefits from various new amenities. Housing prices beyond $1.5 \mathrm{~km}$ from the project site do not response sensitively to the announcements.

The empirical results in this study could be interpreted as general equilibrium effects within $1.5 \mathrm{~km}$ from the project site, but as negligible effects beyond a distance of $1.5 \mathrm{~km}$. Based on the average apartment price for the respective sample period, we calculate the expected price change of an apartment unit following the announcements. The development announcement premium within $0.5 \mathrm{~km}$ amounts to be approximately $\$ 37,900$ (7.3\%) and the remaining net announcement effect after the cancellation to be approximately $\$ 10,900$ (the positive gap of $2.1 \%$ ). The premium for apartments in $0.5-1 \mathrm{~km}$ is approximately $\$ 11,250$, however the net announcement effect is approximately $-\$ 6,266$. Consecutive depreciation following the two announcements in $1-1.5 \mathrm{~km}$ costs approximately $-\$ 25,093$.

The announcement effects may vary depending on the way distance is measured. For example, access to the project site can be a better measure for proximity than a simple straight-line distance. Therefore, we use two alternative distance measurements for proximity - walking distance and driving distance between an apartment and the project site. Both distances are measured by the directions function of Naver Maps. The SDID regression results suggest that the estimated announcement effects are robust regardless of distance measurement; the SDID estimators are almost same with those based on the straight-line distance (see Table A1 in the Appendix).

\section{Conclusion}

This study contributes to the discussion on whether the effect of an amenity development on house prices can be driven by the anticipation about the future housing value growth in advance of the construction. We investigate the effects associated with the announcement of a mega urban redevelopment project in a central urban area in Seoul, South Korea which serves as a natural experiment. The selection of this case is motivated by the case-specific particularities that allow us to measure the announcement effect, isolating it from other development-related effects. We apply a difference-in-differences analysis into a spatio-temporal autoregressive model. The application assesses the announcement effect while controlling for spatial autoregressive behaviour of prices.

The results show significant announcement effects. On the one hand, after the project was announced to the public, apartment prices within $0.5 \mathrm{~km}$ from the project site experience a $7.3 \%$ increase, compared to properties located in the control area. The announcement effect shows a decreasing spatial

pattern. For example, the price premium decreases to $2.4 \%$ in $0.5-1 \mathrm{~km}$ radius from the project site and dissipates beyond $1 \mathrm{~km}$. On the other hand, after the cancellation announcement, we find a significant decrease in apartment prices by up to $5.2 \%$ if they are located within $0.5 \mathrm{~km}$ from the site also gradually 
decreasing with distance. The overall net announcement effect of $2.1 \%$ within apartments located within $0.5 \mathrm{~km}$ from the project could be interpreted as the value of the location premium unveiled by announcements. The net effect on apartment prices within $1 \mathrm{~km}$ from the project site amounts to approximately $\$ 23-26$ million of a speculative increase in property prices despite the fact that the development has not taken place. The effect of the project cancellation is to be seen as the bigger problem as apartments located $1-1.5 \mathrm{~km}$ away from the project experience a reduction in transaction prices of approximately $\$ 100$ million following the development and cancellation announcements in total. This suggests that spatial redistribution of property value takes place during redevelopment announcements and cancellations which is purely speculative.

\section{Appendix.}

\section{Spatio-temporal weight matrix}

The construction of the spatio-temporal weight matrix in this section follows the work of Dubé and Legros (2014), Thanos et al. (2016) and Hyun and Milcheva (2018). Building a spatio-temporal weight matrix $(W)$ is based on spatial and temporal distances between each pair of transactions of apartment units. The measurements are typically represented by an $n \times n$ non-negative matrix where $n$ denotes a number of transactions. At the beginning, all observations are chronically ordered, beginning with the oldest transaction from the first row and the first column. The spatio-temporal weight matrix $W$ is given as:

$$
W=\left(\begin{array}{ccccc}
0 & 0 & 0 & \cdots & 0 \\
S_{21} \times T_{21} & 0 & 0 & \cdots & 0 \\
S_{31} \times T_{31} & S_{32} \times T_{32} & 0 & \cdots & 0 \\
\vdots & \vdots & \vdots & \ddots & \vdots \\
S_{N T 1} \times T_{N T 1} & S_{N T 2} \times T_{N T 2} & S_{N T 3} \times T_{N T 3} & \cdots & 0
\end{array}\right)
$$

where $S_{i j}$ and $T_{i j}$ are value of spatial distance and temporal distance between an apartment $i$ and $j$ respectively. The value of spatial distance $S_{i j}$ is given as:

$$
S_{i j}= \begin{cases}1 / d_{i j}, & \text { if } d_{i j} \leq \bar{d} \\ 0, & \text { otherwise }\end{cases}
$$

where $d_{i j}$ is an Euclidean distance between an apartment unit $i$ and $j$ using geographical coordinates of each apartment and $\bar{d}$ is a critical cut-off value for the spatial relation $(3.5 \mathrm{~km}$ in this study), beyond which other housing transactions are assumed to have no direct spatial impacts. The value of temporal distance $T_{i j}$ is given as:

$$
T_{i j}= \begin{cases}\left(v_{i}-v_{j}\right)^{-1}, & \text { if }\left|v_{i}-v_{j}\right| \leq \bar{v} \\ 0, & \text { otherwise (including if } \left.v_{i}=v_{j} \forall i \neq j\right)\end{cases}
$$


where $v_{i}$ is a temporal value of a transaction of an apartment unit $i$ in a given time period and $\bar{v}$ is a critical cut-off value for the temporal relation (12 months ${ }^{16}$ in this study), beyond which other housing transactions are assumed to have no direct temporal impacts. The value of $v_{i}-v_{j}$ represents the time elapsed between a transaction of apartment unit $i$ and $j$. The general function $v_{i}$ in Equation (15) is defined as:

$v_{i}=12 \times\left(\right.$ yyyy $_{i}-$ yyyy $\left._{\min }\right)+m m_{i} \forall i$

where $y y y y_{i}$ and $m m_{i}$ corresponds to a year and a month of transaction $i$, respectively, and yyy $y_{\min }$ is the first year in the data. As the data used in this study define year and month of transaction, it is not possible to make clear the time order among transactions in the same month $\left(v_{i}=v_{j}\right)$. For the case, zero value is given in order to strictly define unidirectional temporal effects. An inverse form of general function in Equation (14) and (15) ensures that spatially and temporally closer apartment units have larger values (stronger impacts) respectively.

All of the main diagonal elements in the spatio-temporal weight matrix $(W)$ have zero value, as these are relations of an observation on itself. Following the common practice, the matrix is rowstandardised such that the weights sum up to one on each row by dividing each entry by the total value for that row. Given the chronological order of all elements, based on the main diagonal elements, the upper triangular elements in Equation (13) have either a negative value (spatio-temporal impact of a future transaction on a given transaction) or zero (spatio-temporal impact of a transaction in the same month on a given transaction). The spatio-temporal effect occurs from recently sold properties to future sales and not vice versa. Therefore, we assign zero value for the upper triangular elements to rule out the spurious spatio-temporal impact of future transactions on the past ones.

${ }^{16}$ This application provides the best model fit. 
Table A1

SDID estimates for the announcement effect based on the alternative distances

\begin{tabular}{|c|c|c|c|c|c|c|c|c|}
\hline \multirow{3}{*}{ VARIABLES } & \multicolumn{4}{|c|}{ The effect of development announcement } & \multicolumn{4}{|c|}{ The effect of cancellation announcement } \\
\hline & \multicolumn{2}{|c|}{ Walking distance } & \multicolumn{2}{|c|}{ Driving distance } & \multicolumn{2}{|c|}{ Walking distance } & \multicolumn{2}{|c|}{ Driving distance } \\
\hline & Equation (7) & Equation (8) & Equation (7) & Equation (8) & Equation (7) & Equation (8) & Equation (7) & Equation (8) \\
\hline D_Post-DA & $\begin{array}{l}-0.001 * * * \\
(0.002)\end{array}$ & & $\begin{array}{l}-0.001 * * * \\
(0.002)\end{array}$ & & & & & \\
\hline Ring0.5_Post-DA & & $\begin{array}{l}0.073 * * * \\
(0.011)\end{array}$ & & $\begin{array}{l}0.072 * * * \\
(0.011)\end{array}$ & & & & \\
\hline Ring1_Post-DA & & $\begin{array}{l}0.024 * * * \\
(0.005)\end{array}$ & & $\begin{array}{l}0.024 * * * \\
(0.005)\end{array}$ & & & & \\
\hline Ring1.5_Post-DA & & $\begin{array}{l}-0.027 * * * \\
(0.004)\end{array}$ & & $\begin{array}{l}-0.029 * * * \\
(0.004)\end{array}$ & & & & \\
\hline Ring2_ Post-DA & & $\begin{array}{l}-0.024 * * * \\
(0.005)\end{array}$ & & $\begin{array}{l}-0.024 * * * \\
(0.005)\end{array}$ & & & & \\
\hline Ring2.5_Post-DA & & $\begin{array}{l}-0.021 * * * \\
(0.004)\end{array}$ & & $\begin{array}{l}-0.021 * * * \\
(0.004)\end{array}$ & & & & \\
\hline Ring3_Post-DA & & $\begin{array}{l}-0.000 \\
(0.005)\end{array}$ & & $\begin{array}{l}-0.000 \\
(0.005)\end{array}$ & & & & \\
\hline Ring3.5_Post-DA & & Reference & & Reference & & & & \\
\hline D_Post-CA & & & & & $\begin{array}{l}0.010^{* * * *} \\
(0.001)\end{array}$ & & $\begin{array}{l}0.010^{* * * *} \\
(0.001)\end{array}$ & \\
\hline Ring0.5_Post-CA & & & & & & $\begin{array}{l}-0.052 * * * \\
(0.009)\end{array}$ & & $\begin{array}{l}-0.051 \text { *** } \\
(0.009)\end{array}$ \\
\hline Ring1_Post-CA & & & & & & $\begin{array}{l}-0.033 * * * \\
(0.004)\end{array}$ & & $\begin{array}{l}-0.035^{* * * *} \\
(0.004)\end{array}$ \\
\hline Ring1.5_Post-CA & & & & & & $\begin{array}{l}-0.015^{* * *} \\
(0.003)\end{array}$ & & $\begin{array}{l}-0.016^{* * * *} \\
(0.003)\end{array}$ \\
\hline Ring2_Post-CA & & & & & & 0.004 & & 0.004 \\
\hline
\end{tabular}




\begin{tabular}{|c|c|c|c|c|c|c|c|c|}
\hline \multirow{3}{*}{ VARIABLES } & \multicolumn{4}{|c|}{ The effect of development announcement } & \multicolumn{4}{|c|}{ The effect of cancellation announcement } \\
\hline & \multicolumn{2}{|c|}{ Walking distance } & \multicolumn{2}{|c|}{ Driving distance } & \multicolumn{2}{|c|}{ Walking distance } & \multicolumn{2}{|c|}{ Driving distance } \\
\hline & Equation (7) & Equation (8) & Equation (7) & Equation (8) & Equation (7) & Equation (8) & Equation (7) & Equation (8) \\
\hline \multirow{3}{*}{ Ring2.5_Post-CA } & & & & & & $(0.003)$ & & $(0.003)$ \\
\hline & & & & & & -0.003 & & -0.003 \\
\hline & & & & & & $(0.003)$ & & $(0.003)$ \\
\hline \multirow{2}{*}{ Ring3_Post-CA } & & & & & & 0.000 & & 0.000 \\
\hline & & & & & & $(0.004)$ & & $(0.004)$ \\
\hline Ring3.5_Post-CA & & & & & & Reference & & Reference \\
\hline \multirow[t]{2}{*}{ Rho $(\rho)$} & & $0.151 * * *$ & & $0.136^{* * *}$ & & $0.138 * * *$ & & $0.121 * * *$ \\
\hline & & $(0.008)$ & & $(0.008)$ & & $(0.007)$ & & $(0.007)$ \\
\hline Hedonic controls & Yes & Yes & Yes & Yes & Yes & Yes & Yes & Yes \\
\hline Time fixed effect & Yes & Yes & Yes & Yes & Yes & Yes & Yes & Yes \\
\hline Location fixed effect & Yes & Yes & Yes & Yes & Yes & Yes & Yes & Yes \\
\hline Post-period dummy & Yes & Yes & Yes & Yes & Yes & Yes & Yes & Yes \\
\hline Linear effect & Yes & Yes & No & No & Yes & Yes & No & No \\
\hline Radius ring effect & No & No & Yes & Yes & No & No & Yes & Yes \\
\hline Adj- $R^{2}$ & 0.928 & 0.931 & 0.928 & 0.931 & 0.938 & 0.936 & 0.939 & 0.937 \\
\hline Log-likelihood & 18521.101 & 18665.103 & 18510.021 & 18674.212 & 23023.045 & 23176.037 & 23028.054 & 23176.073 \\
\hline AIC & -36874.432 & -37173.246 & -36891.162 & -37185.106 & -45916.117 & -46192.303 & -45917.102 & -46191.303 \\
\hline $\mathrm{BIC}$ & -36361.992 & -36544.254 & -36362.829 & -36564.101 & -45380.730 & -45563.109 & -45382.561 & -45563.175 \\
\hline \multirow[t]{2}{*}{ Observations } & 14,438 & 14,438 & 14,438 & 14,438 & 15,711 & 15,711 & 15,711 & 15,711 \\
\hline & & Standard e & rs in parenthes & $* * * \mathrm{p}<0.01, *$ & $0.05, * \mathrm{p}<0.1$ & & & \\
\hline
\end{tabular}

Note: A coefficient of ring distance (dummy variable) indicates an effect in percentage based on [exp (coefficient)-1] by Halvorsen and Palmquist (1980). 


\section{References}

Ahlfeldt, G.M., 2011. Blessing or curse? Appreciation, amenities and resistance to urban renewal. Reg. Sci. Urban Econ. 41 (1), 32-45.

Ahlfeldt, G.M., Kavetsos, G., 2014. Form or function?: the effect of new sports stadia on property prices in London. J. Roy. Statistical Society 177 (1), 169-190.

Ahlfeldt, G.M., Maennig, W., 2009. Arenas, arena architecture and the impact on location desirability: the case of 'Olympic Arenas' in Prenzlauer Berg, Berlin. Urban Stud. 46 (7), 1343-1362.

Anselin, L., 1988. Spatial Econometrics: Methods and Models. Springer Netherlands, Dordrecht.

Bauer, T.K., Braun, S.T., Kvasnicka, M., 2017. Nuclear power plant closures and local housing values: Evidence from Fukushima and the German housing market. J. Urban Econ. 99, 94-106.

Bowes, D.R., Ihlanfeldt, K.R., 2001. Identifying the impacts of rail transit stations on residential property values. J. Urban Econ. 50 (1), 1-25.

Boyce, D.E., Allen, B., Mudge, R.R., Slater, P.B., Isserman, A.M., 1972. University of Pennsylvania, Department of Regional Science.

Can, A., 1992. Specification and estimation of hedonic housing price models. Reg. Sci. Urban Econ. $22(3), 453-474$.

Case, K., Shiller, R., 1989. The Efficiency of the Market for Single-Family Homes. Amer. Econ. Rev. 79 (1), 125-137.

Case, K.E., Shiller, R.J., 2003. Is there a bubble in the housing market? Brookings Pap. Econ. Act. 2003 (2), 299-362.

Coates, D., Humphreys, B.R., 2006. Proximity benefits and voting on stadium and arena subsidies. J. Urban Econ. 59 (2), 285-299.

Cohen, J.P., Coughlin, C.C., 2008. Spatial hedonic models of airport noise, proximity, and housing prices. J. Reg. Sci. 48 (5), 859-878.

Colwell, P.F., Dehring, C.A., Lash, N.A., 2000. The effect of group homes on neighborhood property values. Land Econ. 76 (4), 615-637.

Dehring, C.A., Depken, C.A., Ward, M.R., 2007. The impact of stadium announcements on residential property values: Evidence from a natural experiment in Dallas - fort worth. Contemporary Econ. Pol. 25 (4), 627-638.

Dröes, M.I., Koster, H.R., 2016. Renewable energy and negative externalities: The effect of wind turbines on house prices. J. Urban Econ. 96, 121-141.

Dubé, J., Legros, D., 2014. Spatial econometrics and the hedonic pricing model: what about the temporal dimension? J. Prop. Res. 31 (4), 333-359.

Dubé, J., Legros, D., Thériault, M., Des Rosiers, F., 2014. A spatial Difference-in-Differences estimator to evaluate the effect of change in public mass transit systems on house prices. Transp. Res.: Part B: Methodological 64, 24-40. 
Gatzlaff, D.H., Smith, M.T., 1993. The impact of the Miami Metrorail on the value of residences near station locations. Land Econ. 69 (1), 54-66.

Gibbons, S., Machin, S., 2005. Valuing rail access using transport innovations. J. Urban Econ. 57 (1), 148-169.

Glaeser, E.L., Gyourko, J., Saiz, A., 2008. Housing supply and housing bubbles. J. Urban Econ. 64 (2), 198-217.

Halvorsen, R., Palmquist, R., 1980. The interpretation of dummy variables in semilogarithmic equations. Amer. Econ. Rev. 70 (3), 474-475.

Hoen, B., Brown, J.P., Jackson, T., Thayer, M.A., Wiser, R., Cappers, P., 2015. Spatial hedonic analysis of the effects of US wind energy facilities on surrounding property values. J. Real Estate Finance Econ. 51 (1), 22-51.

Hyun, D., Milcheva, S. 2018. Spatial dependence in apartment transaction prices during boom and bust. Reg. Sci. Urban Econ., 68, 36-45.

Immergluck, D., 2009. Large redevelopment initiatives, housing values and gentrification: the case of the Atlanta Beltline. Urban Stud. 46 (8), 1723-1745.

Jud, G.D., Winkler, D.T., 2006. The announcement effect of an airport expansion on housing prices. J. Real Estate Finance Econ. 33 (2), 91-103.

Kavetsos, G., 2012. The impact of the London Olympics announcement on property prices. Urban Stud. 49 (7), 1453-1470.

Kiel, K.A., 1995. Measuring the impact of the discovery and cleaning of identified hazardous waste sites on house values. Land Econ. 71 (4), 428-435.

Kohlhase, J.E., 1991. The impact of toxic waste sites on housing values. J. Urban Econ. 30 (1), 1-26.

Lee, B.S., Chung, E.C., Kim, Y.H., 2005. Dwelling age, redevelopment, and housing prices: The case of apartment complexes in Seoul. J. Real Estate Finance Econ. 30 (1), 55-80.

LeSage, J.P., Pace, R.K., 2009. Introduction to Spatial Econometrics. CRC press, London.

Malpezzi, S., 2003. Hedonic pricing models: a selective and applied review, Housing Economics and Public. Blackwell Science, Oxford, pp. 67-89.

McDonald, J.F., Osuji, C.I., 1995. The effect of anticipated transportation improvement on residential land values. Reg. Sci. Urban Econ. 25 (3), 261-278.

McMillen, D.P., 2010. Issues in spatial data analysis. J. Reg. Sci. 50 (1), 119-141.

McMillen, D.P., McDonald, J., 2004. Reaction of house prices to a new rapid transit line: Chicago's midway line, 1983-1999. Real Estate Econ. 32 (3), 463-486.

Mian, A., Sufi, A., 2009. The consequences of mortgage credit expansion: Evidence from the US mortgage default crisis. Quart. J. Econ. 124 (4), 1449-1496.

Michaels, R.G., Smith, V.K., 1990. Market segmentation and valuing amenities with hedonic models: the case of hazardous waste sites. J. Urban Econ. 28 (2), 223-242. 
Nelson, J.P., 2004. Meta-analysis of airport noise and hedonic property values. J. Transp. Econ. Pol. 38 (1), 1-27.

Oates, W.E., 1969. The effects of property taxes and local public spending on property values: An empirical study of tax capitalization and the Tiebout hypothesis. J. Polit. Economy 77 (6), $957-$ 971.

Pope, D.G., Pope, J.C., 2015. When Walmart comes to town: Always low housing prices? Always? J. Urban Econ. 87, 1-13.

Rosen, S., 1974. Hedonic prices and implicit markets: product differentiation in pure competition. J. Polit. Economy 82 (1), 34-55.

Thanos, S., Bristow, A.L., Wardman, M.R., 2015. Residential sorting and environmental externalities: the case of nonlinearities and stigma in aviation noise values. J. Reg. Sci. 55 (3), 468-490.

Tiebout, C.M., 1956. A pure theory of local expenditures. J. Polit. Economy 64 (5), 416-424.

Tomkins, J., Topham, N., Twomey, J., Ward, R., 1998. Noise versus access: the impact of an airport in an urban property market. Urban Stud. 35 (2), 243-258.

Tu, C.C., 2005. How does a new sports stadium affect housing values? The case of FedEx field. Land Econ. 81 (3), 379-395. 